\title{
Metallic muscles and beyond: nanofoams at work
}

\author{
Eric Detsi $^{1,2} \cdot$ Sarah H. Tolbert ${ }^{2} \cdot$ S. Punzhin ${ }^{1} \cdot$ Jeff Th. M. De Hosson $^{1}$
}

Received: 31 May 2015/ Accepted: 30 July 2015/Published online: 14 August 2015

(c) The Author(s) 2015. This article is published with open access at Springerlink.com

\begin{abstract}
In this contribution for the Golden Jubilee issue commemorating the 50th anniversary of the Journal of Materials Science, we will discuss the challenges and opportunities of nanoporous metals and their composites as novel energy conversion materials. In particular, we will concentrate on electrical-to-mechanical energy conversion using nanoporous metal-polymer composite materials. A materials system that mimic the properties of human skeletal muscles upon an outside stimulus is coined an 'artificial muscle.' In contrast to piezoceramics, nanoporous metallic materials offer a unique combination of low operating voltages, relatively large strain amplitudes, high stiffness, and strength. Here we will discuss smart materials where large macroscopic strain amplitudes up to $10 \%$ and strain-rates up to $10^{-2} \mathrm{~s}^{-1}$ can be achieved in nanoporous metal/polymer composite. These strain amplitudes and strain-rates are roughly 2 and 5 orders of magnitude larger than those achieved in common actuator materials, respectively. Continuing on the theme of energy-related applications, in the summary and outlook, we discuss two recent developments toward the integration of nanoporous metals into energy conversion and storage systems. We specifically focus on the exciting potential of nanoporous metals as anodes for high-performance water electrolyzers and in next-generation lithium-ion batteries.
\end{abstract}

Jeff Th. M. De Hosson

j.t.m.de.hosson@rug.nl

1 Department of Applied Physics, Zernike Institute for Advanced Materials, University of Groningen, Nijenborgh 4, 9747AG Groningen, The Netherlands

2 Department of Chemistry, UCLA, 607 Charles E. Young Drive East, Los Angeles, CA 90095-1569, USA

\section{Introduction}

With the emphasis on miniaturization stemming from the electronics industry [1], the same push has been seen in submicron- and nanosized mechanical systems. In medicine and biology, for example, there is a need for highprecision actuators and manipulators for work on fluid filtration and living cell manipulation [2]. The increasingly popular lab-on-a-chip technology takes advantage of highly miniaturized mechanical systems-Micro-Electronic Mechanical Systems or MEMS-to fit efficient analysis systems in a very small space. For progress in these fields, there is a necessity for the continuous development of both materials with micro- and nanoscale functions and of tools that can facilitate the production and characterization of these materials.

Mechanical displacement that comes as a result of an electric signal passing through a material is called actuation. In materials that produce an actuation response, the reverse is often possible as well-an electric current can be induced to flow if the material is deformed. The most common type of material that shows such properties is described as piezoelectric, and of this class of materials, quartz is the most well-known. Indeed, it is the piezoelectric property of quartz that allows it to be used as an oscillating pace mechanism in the common wristwatch [3]. The typical piezoactuator delivers a $\sim 0.2 \%$ strain at a high potential of $150 \mathrm{~V}$ [4]. Considering that it is desirable to see the use of actuation in low-voltage devices, such as MEMS, much lower operational parameters are required for the modern actuating material. Polymer-based actuation materials have been developed, which offer extraordinary capacity for induced deformation, but have the drawback of being weak and compliant. In recent years, we have been exploring metallic nanofoams and have demonstrated the 
potential of nanostructured metals to act as actuators, creating so-called "metallic muscles," with the ability to demonstrate the properties required of the modern actuator: low throughput voltage requirements, high extension yield, strength, and stiffness [5-12]. In this respect, the beautiful work by Weißmüller et al. and the pioneering work by Herbert Gleiter and collaborators have to be mentioned [7, 81.

In this contribution, we will review some aspects of this fast growing field and highlight a couple of ideas of applications in the outlook section that may also have a great impact onto the field of energy-related materials. While the production of nanoporous metallic structures is well-documented, up until recently very little was known about their mechanical properties-at submicron scales, sample size has the possibility to produce a large effect on mechanical properties, where in macroporous foams cell size specifically does not have an influence on material strength [13, 14]. Indeed, it is highly uncertain that the behaviors of macroscopic and microscopic foams will be at all similar in principle and nature. $\mathrm{Li}$ and Sieradzki reported that porous $\mathrm{Au}$ undergoes a ductile-brittle transition that seemed to be influenced by the microstructural length scale of the material [15]. Biener et al. have continued this investigation into the mechanical properties of nanoporous $\mathrm{Au}$ through nanoindentation [10, 16]. They reported the main deformation mechanism during nanoindentation as a ductile, plastic densification. Strong longrange stress fields, brittle fracture, and crack emission were not observed. They note that the scaling laws that are typically applied to macroporous foams apply poorly to nanoporous metals, as they observe experimental yield strength of $145 \mathrm{MPa}$ instead of the expected $16 \mathrm{MPa}$.

Volkert et al. performed microcompression experiments on FIB-milled micronsized pillars of nanoporous $\mathrm{Au}$ with 15-nm diameter ligaments [17]. They find that, while Young's modulus values as determined experimentally and as predicted by scaling laws do not show significant difference, there is a major increase in yield strength as sample size decreases below $50 \mathrm{~mm}$ length scales. A yield strength of $1.5 \mathrm{GPa}$ is predicted, which is several orders of magnitude above that of typical bulk Au. They interpret this effect as influenced by the increased required stress to activate dislocation sources as ligament size decreases, until theoretical shear strength is reached.

Further work by Biener et al. [10, 16] investigated this elevated yield strength whether its origin was the microstructure of disordered nanoporous Au ligaments or the specific size-dependent mechanical properties of $\mathrm{Au}$. This was performed by preparing multiple samples with varying ligament sizes. It is established that in the production of a nanoporous material it is possible to tune ligament and pore size through varying dealloying conditions. They observed a clear influence of ligament size such that the strength of nanoporous Au increases with decreasing ligament diameter, and thus propose that the Gibson and Ashby scaling model of foam plasticity [18] needs to be adjusted to take into account ligament size for nanoporous systems. Recently, we have applied a novel approach to the investigation of deformation of nanoporous metals at the nanoscale by exposing nanoporous nanopillars to $\mathrm{Ga}^{+}$ion beam [19]. It will be not the main topic of this review but it is interesting to note that the results we have obtained with Au nanopillars have also been observed in $\mathrm{Cu}, \mathrm{Al}$, and $\mathrm{Ni}$ nano(porous) pillars, i.e., a gradual massive deformation effect of the pillar during $\mathrm{Ga}$ ion beam exposure, where the pillar bends toward the ion beam. A relationship between the formation of defects due to ion collisions in the nanopillar and the pillar's deformation was derived, and we find that the deflection is linearly related to ion fluence. The high degree of control over deflection and the variables that influence it open an opportunity for use of ion-beam-induced bending as a characterization technique of nano(porous) materials.

Porous systems come in two types-interconnected and noninterconnected (alternatively, open-cell and closed-cell, respectively), describing the relationship of the material's pores: in the former, there exists a continuous pathway between every single pore in the material, and in the latter, the pores exist independently as separated islands. A porous system is typically characterized by a high surface area-to-volume ratio due to the high amount of air-to-solid interface area as well as by a lower density and, by connection, by a lower weight compared to its solid bulk counterpart. To briefly mention terminology, a porous material is made up of pores, struts, and nodes. Pores are the encompassing term for the volume of air within foam and struts are solid material that merge at nodes and connect nodes together.

The popularity of macrofoams, i.e., porous materials where pore size is above the scale of tens of microns, stems from the intersection of a variety of desirable properties in industry. For example, aluminum macrofoam boasts of a high stiffness-to-density ratio, high capacity for energy absorption during compression, high-temperature resistance, electrical and thermal conductivities, good machinability, and cheap production costs [20-25], see Fig. 1. Such properties make macrofoams attractive in the construction and automotive industries, for example. While macrofoams are common materials with known applications in industry, the class of materials known as nanofoams is more exotic. Operating under the same concepts as macrofoams in principle, nanofoams are characterized by pore and strut sizes being at the nanoscale, in other words the greatest diameter of a pore or strut must be considered a nanoscale dimension. For a more precise 

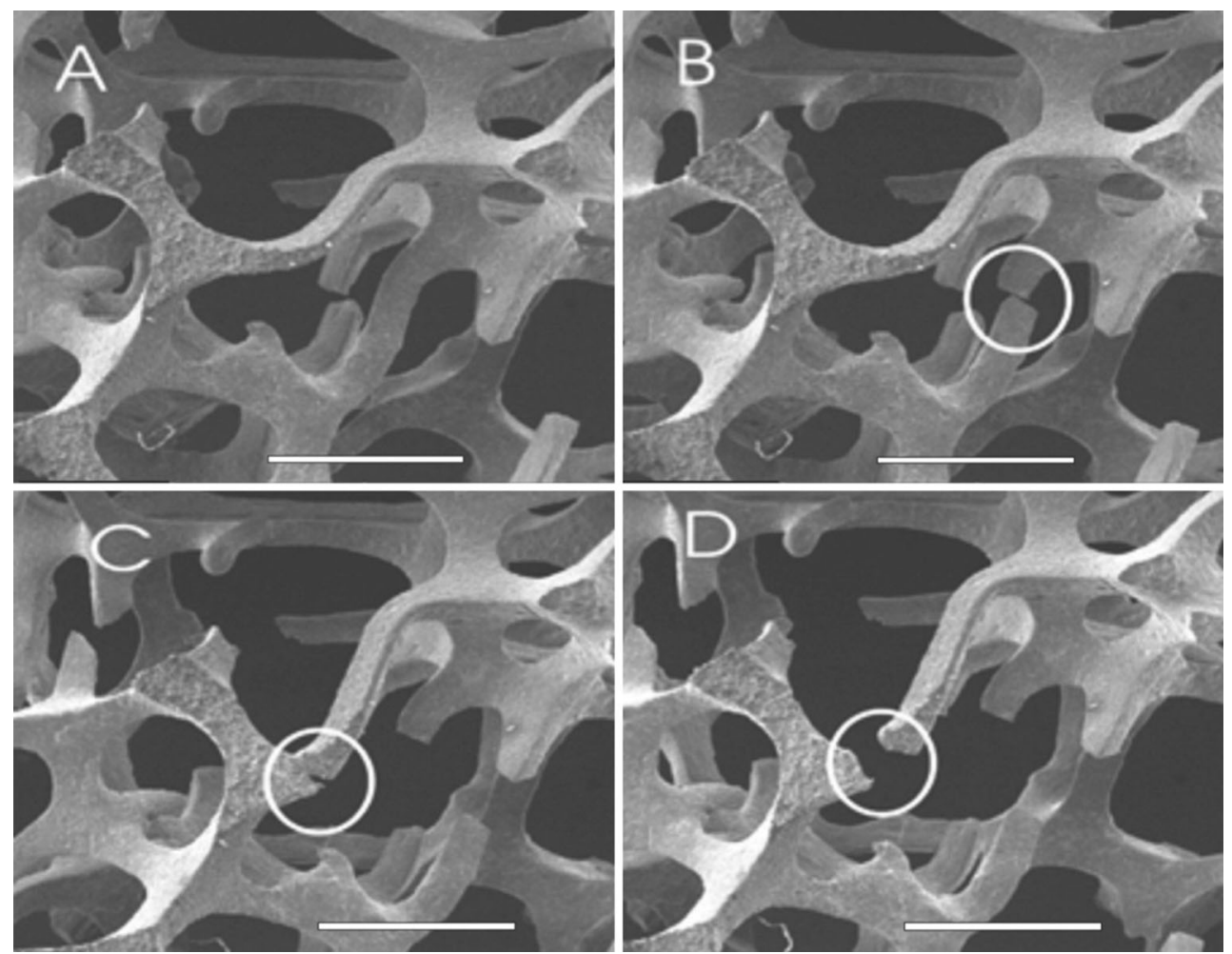

Fig. 1 In-situ deformation in a Philips XL30-FEG-ESEM of Duocel 40 PPI macro foam with a relative density of approximately $7 \%$ (scale bar $1 \mathrm{~mm})$

definition, the International Union of Pure and Applied Chemistry has categorized nanoporous metals into three groups, depending on the pore size: microporous metals have pore size under $2 \mathrm{~nm}$, mesoporous metals have pore sizes between 2 and $50 \mathrm{~nm}$, and macroporous metals have pore size above $50 \mathrm{~nm}$.

Nanofoams share many properties with their macrofoam counterparts, such as the high surface-area-to-volume ratio, but also including the capacity for cheap production and easy machinability. In addition, however, nanoporous foams have seen usage in many applications beyond those of macrofoams, including nanofiltration systems, drug delivery platforms, catalysis, sensing, and actuation [26-35]. A major advantage that nanoporous metals have is the ability to hold a lattice of nanoscale features while being able to be easily handled and transported, something metallic nanoparticles, for example, cannot provide.

The contribution for this Golden Jubilee issue of the Journal of Materials Science will be focused on the actuating properties of metallic foams, although these materials turned out be also sensors [36, 37]. In the Discussion section, we also present an outlook onto two promising energy-related fields, involving oxygen evolution and $\mathrm{Li}$ ion battery, in which porous metals may have a large impact.

\section{Metallic muscles: why does it work ?}

The actuation mechanism in common artificial muscles makes use of microscopic phenomena in the bulk of the material such as dipoles polarization. In piezoceramics, for instance, asymmetry in the crystal lattice structure gives rise to domains with electric dipole moments. These dipole moments are randomly oriented, and they can be aligned with an external electric field [38]. Dipole alignment through the bulk of the material results in macroscopic dimensional changes. In metallic muscles, not only the bulk volume but also the interface surface area plays a central role during actuation. As a starting point, the fact that surface atoms in crystalline materials have a lower coordination than those in the bulk results in an excess bonds' charge at a newly created surface. This excess charge redistributes at the surface to strengthen the interatomic bonds and shorten the distance between surface atoms [39]. This results in a positive surface stress (tensile stress) in the material at mechanical equilibrium of the material system (i.e., a tensile displacement to bring the atoms back to an equilibrium distances as in the bulk). That situation is schematized in Fig. 2 in the case of metallic bonding. The red circles represent positive metal ions (cations) consisting of nuclei and inner-shell electrons; the ovals illustrate delocalized free electrons in the bulk (light 
(a)

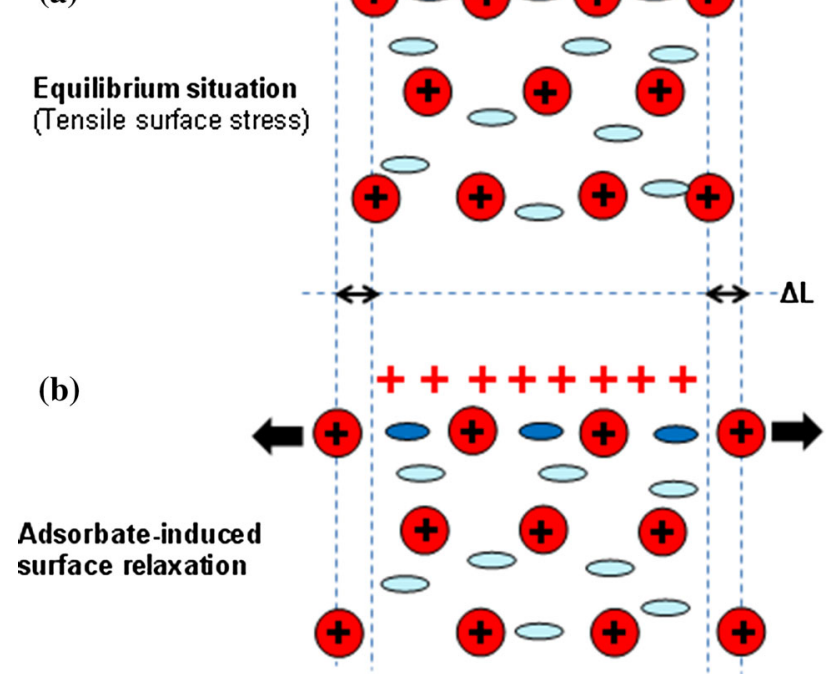

Fig. 2 Actuation mechanism in metallic muscles. a A clean metal surface exhibits a tensile surface stress at equilibrium, resulting in the reduction of the interatomic distance. b Adsorbates with excess positive charges at the metal surface remove the bonds charge between surface atoms, inducing surface relaxation

blue ovals) and at the surface (dark blue ovals) of the metal. It can be seen in Fig. 2a that at mechanical equilibrium, the interatomic distance is reduced due to the tensile surface stress [40] with respect to the bulk.

The charge distribution at the metal surface (dark blue ovals in Fig. 2) can be controlled in different ways, for instance, by bringing a layer of adsorbates at the interface [41]. A positive charge of the adsorbate will result in an electronic charge redistribution at the metal surface. It generates a lower tensile surface stress and results in a relaxation of the surface atom positions by increasing the interatomic spacing. In order to preserve the mechanical equilibrium [42], bulk atoms experience less compressive stress and move in a positive direction outward, as illustrated in Fig. 2b. Therefore, since detection is due to the bulk atoms, a positive displacement is measured experimentally. Although these surface stress-induced bulk deformations are not detectable in macroscopic metals, they become significant in nanostructured metals where the properties are governed by the large surface area, rather than by the bulk volume as highlighted above. This phenomenon represents the basic operating principle of metallic muscles which consist of nanoporous metals with high surface-area-to-volume ratios.

The electronic charge distribution at a nanoporous metal interface can also be easily controlled in an aqueous electrolyte where an electrical voltage is used to bring positive or negative charge carriers (i.e., ions) from the electrolyte to the nanoporous metal interface. Typically, referring to the above-mentioned actuation mechanism in metals, injection of negative charge in the space-charge region at a nanoporous metal/electrolyte interface during electroadsorption of charge compensating positive ions enhance the tensile surface stress in the metal [8, 43], resulting in an increase in compressive stress in the bulk of the ligaments and in an overall macroscopic volume shrinkage of the nanoporous metal specimen $[8,44]$, i.e., a negative displacement is measured experimentally.

As highlighted above, nanoporous metal actuators offer a unique combination of low operating voltages, relatively large strain amplitudes, high stiffness, and strength. Despite these remarkable features, the emergence of nanoporous metal actuators in practicable applications is still delayed, a decade after their discovery $[7,8]$. The challenge to their further development in viable applications can be considered threefold, but principally concerns the aqueous electrolyte that is needed to inject electronic charge in the space-charge region at the metal/electrolyte interface [45]:

- At first, an aqueous electrolyte limits the usage of metallic muscles to wet environments whereas most of the practical applications require artificial muscles that can operate in dry environments.

- A second major concern is that the aqueous electrolyte limits the actuation rate because of its relatively low ionic conductivity. Simply replacing the aqueous electrolyte by a solid one is an obvious solution but the actuation rate of all-solid-state electrochemical actuators is more severely hampered by the low roomtemperature ionic conductivity of solid-state electrolytes.

- Completing the trio of challenges is the fact that the ligaments in nanoporous metals suffer from severe coarsening (undesired growth) during electrochemical processes [46] including actuation via redox reactions. Coarsening causes metallic muscles to lose performance efficiency after many cycles, because the charge-induced strain is ligament size-dependent as shown in Fig. 3 where strain amplitudes are plotted as a function of the ligament size. This shows that the growth of the ligaments during performance of electrochemical actuation is undesirable.

In addition to these technical boundaries, it is emphasized that metallic muscles operating as electrochemical actuators require a three-component configuration to function; explicitly these are a working electrode, an electrolyte, and a counter electrode. In such a configuration, the working and counter electrodes, which may separately actuate as demonstrated by Kramer et al. [9], are placed at a relatively large distance from each other. This fixed distance represents a limitation for the integration of metallic muscles into miniaturized devices [47]. In view of 
Ligament diameter

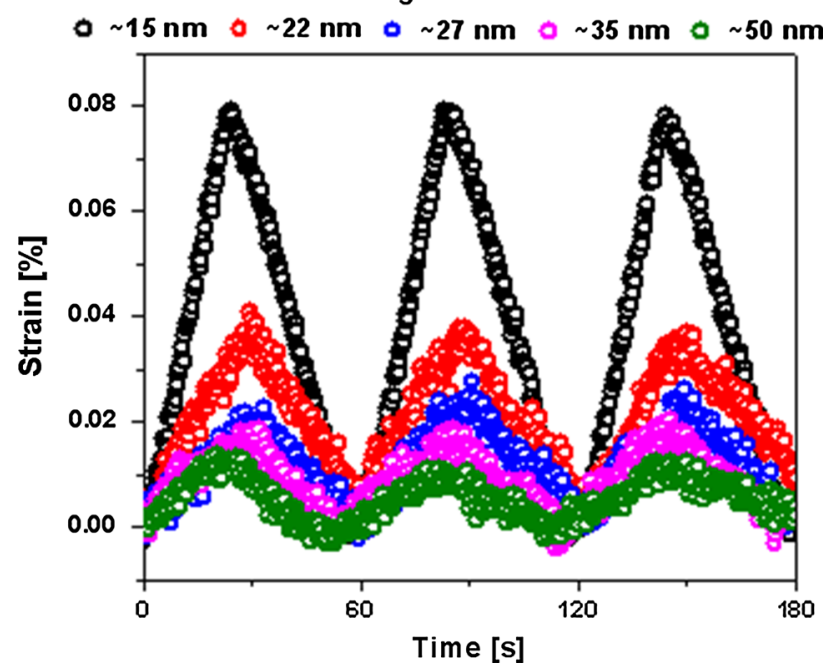

Fig. 3 Ligament size-dependence of the charge-induced strain in nanoporous metals. The strain amplitude recorded on five NPG samples with different ligament sizes decreases with the increasing ligament size. This shows that ligaments' growth during electrochemical actuation is undesirable (Color figure online)

these various restrictions caused by the electrolyte, an electrolyte-free approach is desirable for actuation in nanoporous metals. In fact, the following features are a prerequisite for a breakthrough in the field of artificial muscles: (i) no usage of aqueous or solid electrolyte, (ii) a fast actuation rate, and (iii) a single actuating component as in piezoelectric materials.

\section{Processing}

In the majority of cases, metal nanofoams are produced through dealloying. In the literature, several processing conditions and results are highlighted and reference can be made to [48-60]. For this process to work, an alloy must be produced between the required metal and another that can be etched away in some manner. It is also required that the two metals be able to form a solid solution, as any other morphology will not allow for the eventual formation of an isotropic structure of pores and ligaments. This is often the limiting factor for the dealloying process of nanofoam manufacture, as many metals do not easily form solid solutions, and if they do, it may not be possible to selectively etch one of the components of the alloy system while leaving the other intact. A typical example of a dealloyed $\mathrm{Au}-\mathrm{Ag}$ system is displayed in Fig. 4. Without going into details in [61]. we present a Metropolis Monte Carlo study of the dealloying mechanism leading to the formation of nanoporous materials. A simple lattice-gas model, for gold, silver, and acid particles, vacancies, and products of chemical reactions, is adopted. The influences of temperature, concentration, and lattice defects on the dealloying process are investigated, and the morphological properties are characterized in terms of the Euler characteristic, volume, surface area, and the specific surface area [21]. It is shown that a minimal three-parameter model suffices to yield nanoporous gold structures which have morphological properties akin to those found in the experiment. The recent technique of Transmission Electron Back-Scatter Diffraction was used by us [62] to investigate the effect of dealloying on the microstructure of 140-nm-thin gold foils. Transmission electron backscatter diffraction (t-EBSD) combines the detection of Kikuchi bands of forward-scattered electrons with the scanning possibilities of the scanning electron microscope (SEM). This technique was first suggested by Keller and Geiss [63]. The terms SEM transmission Kikuchi diffraction (SEM-TKD) [64] and transmission electron forward-scattered diffraction ( $t$ EFSD) $[65,66]$ are coined as more appropriate alternatives. Although the acronym t-EBSD may sound peculiar, it describes the technique very well: transmission microscopy in an EBSD system. A global (statistical) and a local comparison of the microstructure between the nonetched and nanoporous gold foils were made. Characterizations of crystallographic texture, misorientation distribution, and grain structure clearly prove [67] that during formation of nanoporous materials by dealloying, the crystallographic texture is significantly enhanced with a clear decrease of internal strain while retaining the grain structure.

Silver is alloyed with gold to form the so-called "white gold," an alloy commonly used in jewelry. The versatility of the alloy stems from its ability to form a solid solution at any ratio of gold to silver allowing for fine control of porosity of a resultant pure gold system. While copper does not have alloy systems as simple as gold's with silver, copper-manganese forms a reliable solid solution across a wide range of compositions [68, 69]. Unfortunately, except at very low percentages, Mn tends to segregate out of the solid solution and form a phase of pure Mn at low temperatures. This issue is solved through rapid quenching from solid solution temperature. This process prevents the formation of the pure Mn phase and, provided that the quenching had occurred successfully, yields an ingot with a microstructure comparable to that of $\mathrm{Ag}$ - $\mathrm{Au}$ alloy.

As is often the case for many novel materials, interest in producing a nanoporous structure with an ordered, anisotropic pore structure came from observing nature. Specifically, the opalescence effect-variation in color based on direction of observation-seen in butterfly wings and mother-of-pearl stems from the ordered chitinous scales for the former or calcium plates for the latter serving as photonic diffraction gratings. The brilliant color variation is a light effect described as opalescence and is a result of an 
Fig. 4 Microstructural characterization of NPG/PANI. a Scanning electron micrograph showing the bicontinuous morphology of NPG. $\mathbf{b}$, c Scanning and transmission electron micrographs showing a $\sim 5$-nm-thick PANI skin covering the ligaments of NPG. The inset of c displays the EDX spectrum of PANI. C and $\mathrm{N}$ come from aniline $(\mathrm{C} 6 \mathrm{H} 7 \mathrm{~N}), \mathrm{Cu}$ and $\mathrm{Au}$ come, respectively, from the $\mathrm{Cu}$ grid used as sample holder and the NPG. d Fracture cross section of NPG/PANI; It can be seen that the polymer envelope covering the ligaments is present in the bulk of the composite material
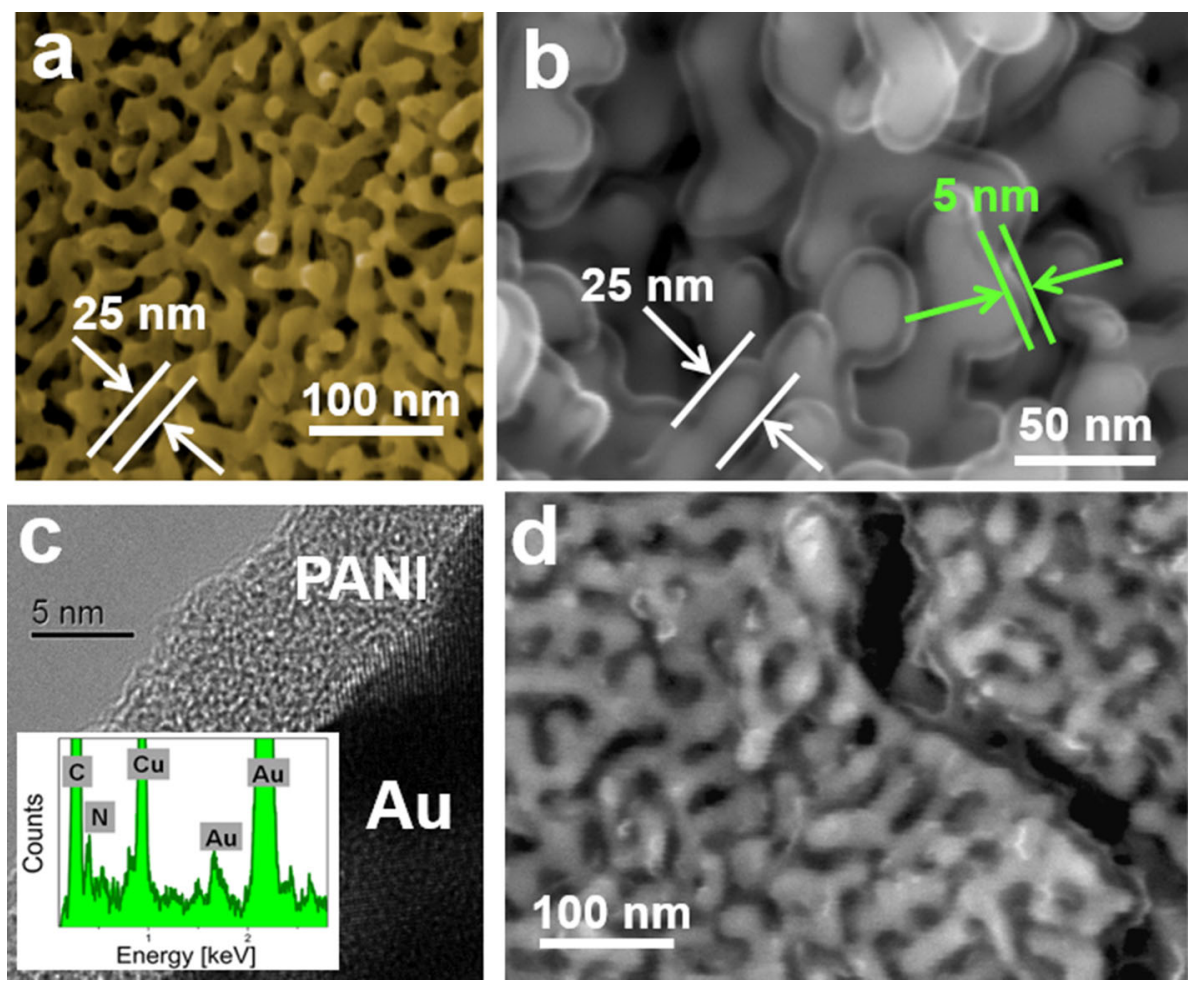

ordered nanoporous lattice acting as a series of waveguides, only permitting through light of a particular frequency depending on viewing direction. The use of waveguide materials such as this has been proposed for use in optical circuitry [70, 71].

With clear applications across many industries, [72-75], three-dimensionally ordered materials have garnered much attention. As with all nanostructured materials, two methods of approach are viable for their production: top-down and bottom-up. Top-down production focuses on reducing a bulk source sample down to the correct size, shape, and morphology through a variety of destructive production methods. While the top-down method boasts a very logical application with easy potential for iterative improvement, its greatest limitation is the scale down to which its production methods can reach-detail at the nanometer scale is beyond the capabilities of the typical top-down method [76-78]. The alternative is the bottom-up approach, where nanoscale features are assembled piece by piece into a full structure. This method allows for far finer detail control and overall quality of the assembled structure, but is typically challenging to implement due to it often being a multistage process.

The top-down process of production of nanostructured materials typically involves a starting bulk macroscale solid and then the use of one of several techniques to achieve a nanostructure through size reduction. In medical applications, a top-down method for the production of nanoparticle suspensions is high-pressure homogenization, consisting of the repeated forcing of a suspension through a very thin gap at high velocity or media milling, which is the mechanical attrition of suspended particles using glass or zirconium oxide [79]. Mechanical attrition in general is a common procedure for the production of nanostructured materials, and one example of such a procedure is the method of ball milling, where powders are sealed in a strengthened container with a set of hard metal spheres and treated in a vibratory mill to elicit potential phase changes and the formation of nanostructured grains in the processed particles [80]. More nonstandard procedures are also known: Yan et al. have proposed that, considering its simplicity and capacity for high-resolution spatial imaging, an atomic force microscopy (AFM) apparatus can be used to machine nanoscale features, and have demonstrated this capability in aluminum [81].

As a whole, lithography is considered a top-down method, and is common in the electronics industry for the production of microchips. However, it can be converted into a bottom-up method by reducing the size of the initial template. This idea can be applied for 3D nanostructures: a porous 3D template is constructed that allows for the introduction of a particular material into the pore spaces within the template. After the template is removed, the result is a 3D "image" of the template's pore network. This is called inverse templating, and is the principal bottom-up method that allows for repeatable batch production in 
moderately large quantities, provided that the template is easily constructed. For this purpose, self-assembling templates are highly valued-templates whose component parts can, over time, arrange themselves into a desired 3D pattern with no further intervention aside from the initial process setup.

Nanosphere templating uses the natural ability of silica or polymer (PMMA, polystyrene, latex) nanospheres to reliably self-assemble into a template on a large scale. The nanospheres are suspended in a solution and are allowed to naturally settle over time, although centrifugation can be used to accelerate the process at the expense of quality of ordering. An alternative method is to allow the spheres to settle across a meniscus to improve ordering with the downside of the resultant template film being very thin. The spheres will preferentially settle into their most lowenergy configuration, which is a crystalline face-centered cubic arrangement. As the nanospheres settle, the solution evaporates and eventually a dry nanosphere template remains.

A settled nanosphere template is typically a weak, brittle solid, as the spheres are held together only through van der Waals forces. Thermal processing can be applied to strengthen a finished template by furnace-treating the template to allow necks to form between adjacent spheres. The appropriate temperature and time vary significantly by material, e.g., several minutes at $120^{\circ} \mathrm{C}$ is enough for polymers like polystyrene, and processing for several hours at over $900{ }^{\circ} \mathrm{C}$ is required for silica. This results in a much more robust template that can withstand mechanical rigor, but it may be more challenging to remove. See Fig. 5.

In principle, any sort of material with submicron-scale features, which exhibits ordering can be used as a template, provided that interconnected voids exist between the features. One such material is the so-called "block copolymer." In such a material, two covalently linked polymers,

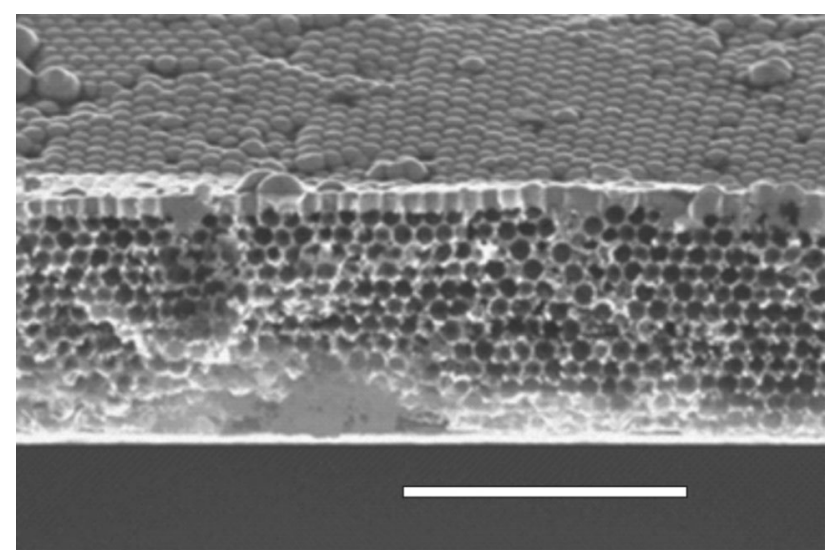

Fig. 5 SEM micrograph of electroless plated nanosphere template on gold-plated silicon wafer after template removal (scale bar $5 \mathrm{~mm}$ ) or blocks, undergo a process called microphase separation, i.e., attempt to separate as oil and water would, but are limited in their capacity to do so due to crosslinking. An enthalpy-entropy balance governs the specific manner in which this separation occurs. By controlling the compositions of the component block, it is possible to influence the phase behavior of the copolymer and thus form a variety of phases: lamellar, cylindrical, and spherical phases are common, while classical phases, with the perforated lamellar, gyroidal, and ordered bicontinuous double diamond phases are seen more rarely. In all cases, depending on the composition, one block forms the specific feature that the morphology is named after. and the other forms a matrix around the feature. Remarkably, all resultant structures show a high degree of ordering of their characteristic unit cell. As such, if, once a particular phase has been formed, one of the blocks of the copolymer could be removed while leaving the other preserved; the resultant polymer matrix could be used as an organic template. Of the possible phases formed by diblock copolymers, the gyroid phase is the most interesting due to its repeating, long-ranged ordering of a three-dimensional feature. In other words, the gyroid morphology offers the strongest potential for use as a template to produce a three-dimensionally ordered nanofoam. Recently, we have investigated this route via supramolecular PS-b-P4VP(PDP) (diblock copolymers of polystyrene and poly(4-vinylpyridine)) complexes with a bicontinuous gyroid morphology that were used as templates to produce metallic nickel nanofoams [82]. The complete dissolution of PDP from the complex with the major P4VP(PDP) component forming the matrix results in an open network structure with struts consisting of a PS core and a P4VP corona. The high specific surface area and the narrow pore size distribution of the structure formed are evidenced by nitrogen adsorption and mercury porosimetry. The open nature of the pores allows for electroless deposition of metal. During the processing, the symmetry and the size of the nanopattern are conserved. The subsequent removal of the polymer template by pyrolysis leads to the formation of an inverse gyroid nickel nanofoam with porosity exceeding $50 \% \mathrm{v} / \mathrm{v}$ (see Fig. 6). The use of polymer templates with different compositions and sizes of the domains enables further tuning of the porosity characteristics.

It should be realized that the nanostructured metallic foams can show rather brittle behavior [83, 84] (although we found way to circumvent that problem by making layered stacks [44]). Recently, Weißmüller and co-authors [85] investigated the anomalous compliance and early yielding of nanoporous gold by molecular dynamics simulation pointing out that nanoporous gold can be deformed to large strain in compression, but with very high strainhardening coefficient. As regards brittleness, we have 

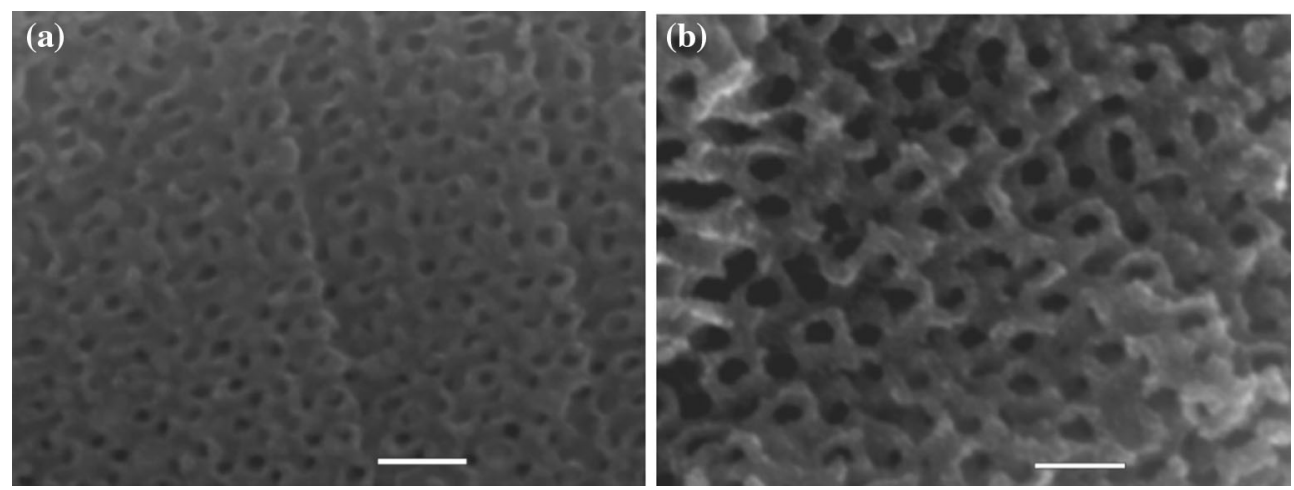

Fig. 6 SEM images of the inverse gyroid nickel replicas obtained after the polymer template removal by pyrolysis (pyrolysis time $=\mathbf{a} 1$ day, b 4 days). A 3D network structure composed of the interconnected nickel struts is clearly visible (scale bar $100 \mathrm{~nm}$ )

investigated size effects of these nanoporous materials. It is not difficult to understand that upon decreasing diameter (aspect ratio 3 because of stability) a lower stiffness is expected since a larger fraction of loosely bound struts appears whereas under pure shear the opposite will be observed (because of increasing fraction of confined material). Focused Ion Beam was employed to fabricate pillars with a controlled taper free shape. The use of nontapered pillars prevents localization effects due to variation in diameter across the compression axis. Indentation experiments were carried out on the freestanding nontapered nanoporous metal pillars. Pillars were produced from both disordered nanoporous $\mathrm{Au}$ as well as ordered nanoporous Ni. Pillars produced in such a manner fully retained their porosity, as well as quality of ordering.

Two modes of deformation were observed during indentation (Fig. 7): brittle fracture and ductile deformation with limited recovery. In the former, the pillar would spontaneously fracture at a particular load without developing any significant deformation prior. In the latter, the pillar would be observed to undergo a gradual bend without fracture until load release, where the pillar would partially regain its original shape. Full recovery was not observed due to the development of minor fracture regions during initial loading. Subsequent loads on the same pillar after recovery would increase the size of the fracture, leading to stress localization in subsequent loads and eventual spontaneous fracture nucleating from the affected area. It was observed that the tendency toward gradual deformation over spontaneous fracture was dependent on pillar diameter such that thinner pillars would deform gradually. Typically, pillars under 300-400-nm diameter would be thin enough for such behavior, and thicker pillars would be more likely to undergo spontaneous fracture. It is worth emphasizing that in all indentation experiments where gradual deformation was the mode of deformation the nature of deformation was a bending, as opposed to a pure compression as would be expected from an indentation test.
This tendency made for challenging prediction on the true behavior of nanoporous pillars under compression, as bending adds additional deformation components to the otherwise simple cell wall buckling model of the effects of the compression of porous media. This bending stemmed from the specific design of the Hysitron Picoindenter, where the indentation tip is aligned such that, if a sample is sufficiently small, there is only a very specific set of sample positions and orientations that would allow for pure compression.

\section{Electrolyte-free actuation in metallic muscles}

As already aforementioned in Sect. 1, an important objective is to overcome the limitations that arise in metallic muscles when an aqueous electrolyte is used for actuation: existing metallic muscles made of nanoporous metals with high surface-area-to-volume ratios can exert work due to changes in their interface electronic charge density. However, they suffer from serious drawbacks caused by the usage of an aqueous electrolyte needed to modulate the interface electronic charge density by injection of electronic charge at the nanoporous metal/electrolyte interface. An aqueous electrolyte prohibits metallic muscles to operate in dry environments and hampers a high actuation rate due to the low ionic conductivity of electrolytes. Simply replacing the aqueous electrolyte by a solid is an obvious solution, but the actuation rate of allsolid-state electrochemical actuators is more severely hampered by the low room-temperature ionic conductivity of solid-state electrolytes. In addition, redox reactions involved in electrochemical actuation severely coarsen the ligaments of nanoporous metals, leading to a substantial loss in performance of the actuator. We have developed a new electrolyte-free concept to put metallic muscles to work via a metal/polymer interface [12]: A nanocoating of polyaniline (PANI) doped with sulfuric acid was grown 


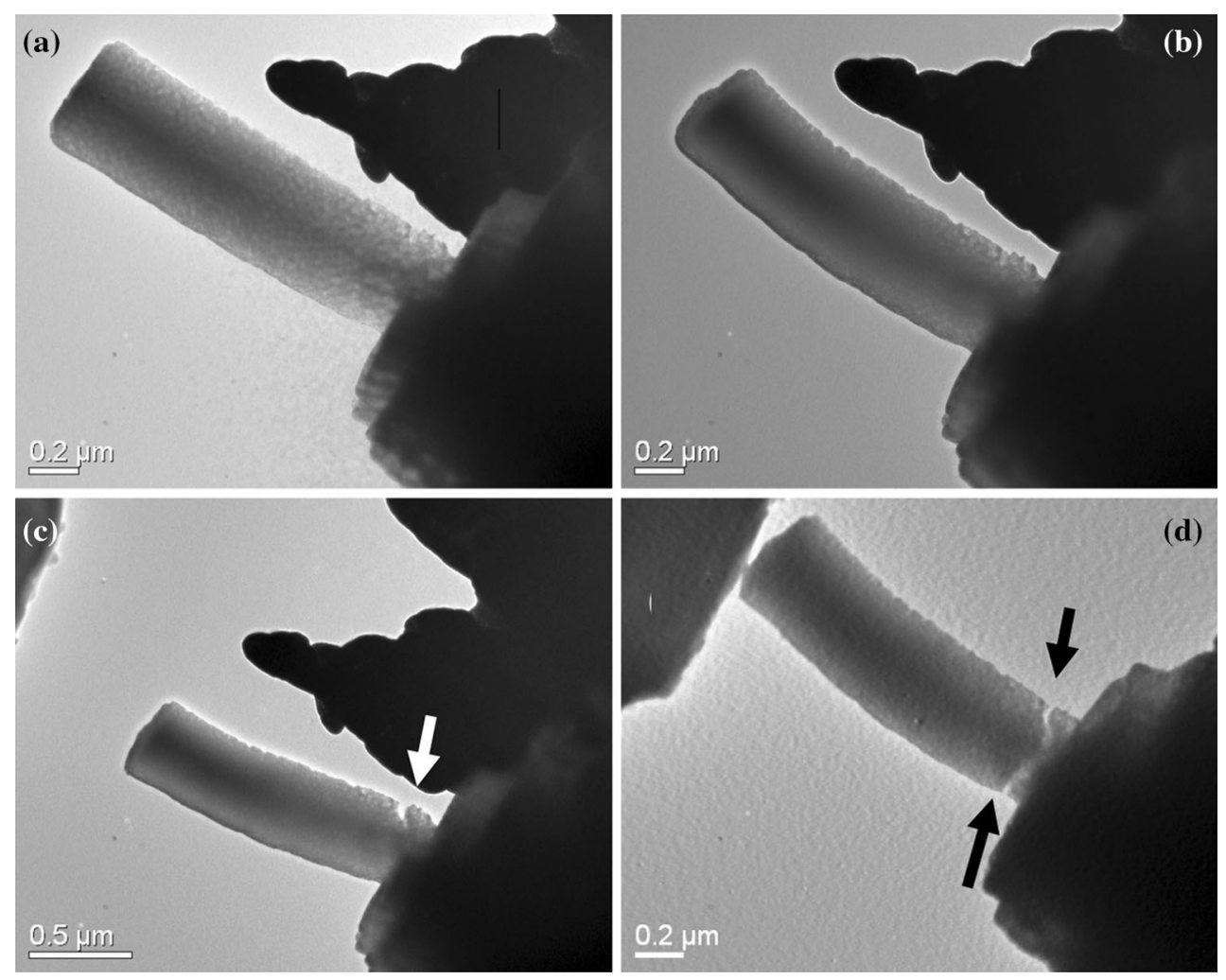

Fig. 7 TEM micrograph of initial pillar (a), during loading (b), after loading with recovery and after subsequent loads (d). Minor fracture indicated by arrows after initial load is visible and the expansion thereof after subsequent loading

onto the ligaments of nanoporous gold (NPG). Dopant sulfate anions co-adsorbed in the polymer coating matrix were exploited to tune the electronic charge density at the NPG interface and subsequently generate macroscopic dimensional changes in NPG. Strain rates achieved in the single-component NPG/PANI bulk heterojunction actuator are three orders of magnitude higher than that of the standard three-component nanoporous metal/electrolyte hybrid actuator. Also the combination of a nanoporous metal and a polymer has been further exploited to add a new functionality to metallic muscles operating as electrochemical actuators: in addition to the reversible dimensional changes in the nanoporous metal, the polymer undergoes reversible changes in color when it is electrooxidized/reduced. This results in a smarter hybrid actuation material.

To show the proof of principle here: NPG was synthesized by the standard dealloying method, and the typical bicontinuous morphology of the synthesized NPG is shown on the scanning electron micrograph is shown in Fig. 4. The corresponding interface surface area per unit mass computed from the analytical expression for the specific surface area of nanoporous materials [86-89] was found to be $\sim 7.7 \mathrm{~m}^{2} \mathrm{~g}^{-1}$. The internal surface area of the threedimensional bicontinuous network of the synthesized NPG was uniformly coated by electropolymerization procedure, and a continuous doped polymer envelope covers the ligaments $[90,91]$. The potentiodynamic procedure (i.e., monomers deposition with a variable voltage via cyclic voltammetry) was used [92], and the polymerization of aniline was carried out from an aqueous solution containing $50 \mathrm{mM}$ of aniline monomer and $0.5 \mathrm{M}$ of $\mathrm{H}_{2} \mathrm{SO}_{4}$ used as solvent and dopant molecules, respectively [90]. The scanning and transmission electron micrographs of Fig. 4 display a uniform PANI skin of average thickness of $\sim 5 \mathrm{~nm}$ grown onto the ligaments of NPG. The presence of carbon $(\mathrm{C})$ and nitrogen $(\mathrm{N})$ as constituents of the organic coating monomer $\mathrm{C}_{6} \mathrm{H}_{7} \mathrm{~N}$ (aniline) was confirmed by energy-dispersive X-ray spectroscopy (EDS) performed during characterization of the PANI film by transmission electron microscopy (TEM). The typical EDS spectrum of this PANI envelope is displayed in the inset of Fig. 4c. In this energy spectrum, the $\mathrm{Cu}$ and $\mathrm{Au}$ peaks are attributed to the $\mathrm{Cu}$ grid of the sample holder and to the NPG, respectively. The scanning electron micrograph of Fig. $4 \mathrm{~d}$ represents a fracture cross section of the NPG/PANI hybrid material. It can be seen that the nanocoating of polymer covering the ligaments of NPG is present in the bulk of the material. Detailed knowledge of the nature of electronic charge transport in the PANI film is necessary for a better 
insight into the actuation mechanism in the NPG/PANI hybrid material. A schematic illustration of this NPG/PANI bulk heterojunction actuator is shown in Fig. 8a-d, and additional technical details are found in [93]. The actuator is connected to the voltage supplier in one of the following two configurations: NPG/PANI/Au with NPG as anode and solid $\mathrm{Au}$ as cathode, or Au/PANI/NPG with solid Au as anode and NPG as cathode. Both configurations can be used because the two contact electrodes (NPG and solid $\mathrm{Au}$ ) are made of the same material. Since the work functions of NPG and solid Au are comparable with the highest occupied molecular orbital (HOMO) of PANI on the one hand [94], and since PANI is a p-type semiconductor on the other hand [95], electronic charge transport in the NPG/ PANI hybrid actuator is only controlled by holes conduction, rather than by both electrons and holes transports. Such a single carrier system is commonly referred to as a "hole-only" device because the high offset between the Fermi level of the metal and the lowest unoccupied molecular orbital (LUMO) of PANI restricts electrons injection from the metal into the LUMO of the polymer [96]. The energy-level diagram of the NPG/PANI/Au system in the absence of external electrical potential is shown in Fig. 8e; it is seen that only holes can be injected from the anode into the HOMO of PANI.

An external electric potential was used to inject holes from the metal anode (either NPG or solid $\mathrm{Au}$ ) into the HOMO of the PANI envelope [97]. A particularity of the $\mathrm{NPG} / \mathrm{PANI} / \mathrm{Au}$ or $\mathrm{Au} / \mathrm{PANI} / \mathrm{NPG}$ configuration is that electronic charges injected from the anode flow through the PANI film before reaching the cathode. The typical current density-voltage $(J-V)$ characteristic of the Au/ PANI/NPG system (holes injection from $\mathrm{Au}$ ) is shown on the semi logarithmic plot of Fig. 9. The inset of Fig. 9a displays the corresponding forward $J-V$ curve on a double logarithmic graph. Similarly, the $J-V$ curve of the NPG/ $\mathrm{PANI} / \mathrm{Au}$ system (holes injection from NPG) is shown on the semi logarithmic plot of Fig. $9 b$ for three successive forward-backward voltage sweeps in the same potential range between 0 and $2 \mathrm{~V}$. The inset of Fig. $9 \mathrm{~b}$ displays the corresponding forward $J-V$ curve on a double logarithmic plot. The hysteresis [98] in the $J-V$ curves are more pronounced when holes are injected from solid $\mathrm{Au}$ (Fig. 9a) than from NPG (Fig. 9b); this can be caused by the difference in contact area for holes injection, which is larger for the NPG/PANI interface than the Au/PANI interface. Irrespective of this difference, it can be concluded from the slope values of 1 obtained on the double logarithmic graphs for both Au/PANI/NPG and NPG/ PANI/Au configurations (see insets of Fig. 9a, b) that at low potentials, electronic charge transport through the polymer skin follows an Ohmic behavior at ambient temperatures [99]. A similar Ohmic behavior has been reported when the two contact electrodes are made of solid $\mathrm{Au}$ in the $\mathrm{Au} / \mathrm{PANI} / \mathrm{Au}$ configuration [12]. It is emphasized that the Ohmic nature of the current in the NPG/PANI hybrid actuator means that electronic charges do not accumulate at the metal/polymer interface during potential sweeps, in the contrary of a metal/electrolyte actuator where a (pseudo)capacitive double-layer formed at the metal/electrolyte interface is used for actuation. Therefore, the approach presented here for the modulation of the electronic charge density at the NPG/PANI interface is different from the building up of space-charge encountered in nanoporous metal/electrolyte hybrid materials.
Fig. 8 The NPG/PANI bulk heterojunction actuator. a, $\mathbf{c}$ The main part of the actuator consists of NPG whose ligaments are coated with a $\sim 5$ $\mathrm{nm}$ layer of PANI. b One edge connected to the positive terminal of the voltage supplier consists of NPG. d The other edge connected to the negative terminal consists of NPG having its ligaments covered with $\sim 10$-nm-thick layer of PANI. e Energy-level diagram of the system NPG/PANI/Au system in the absence of external electrical potential

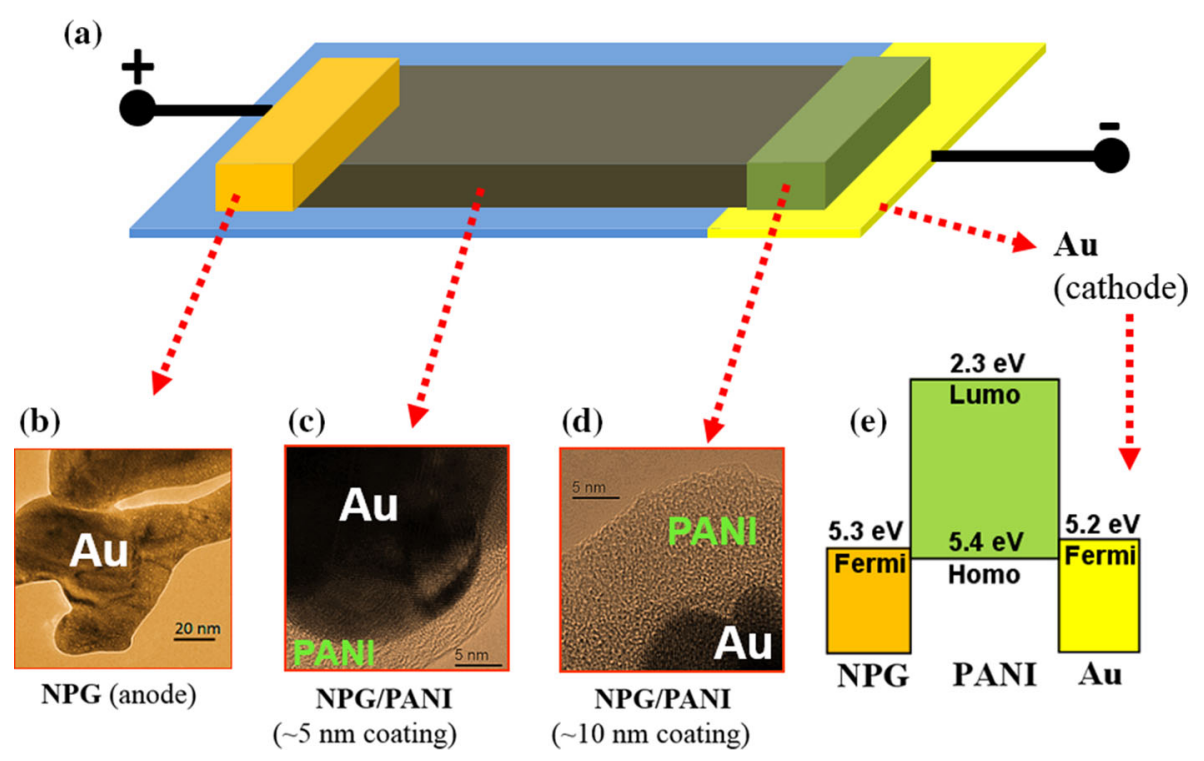




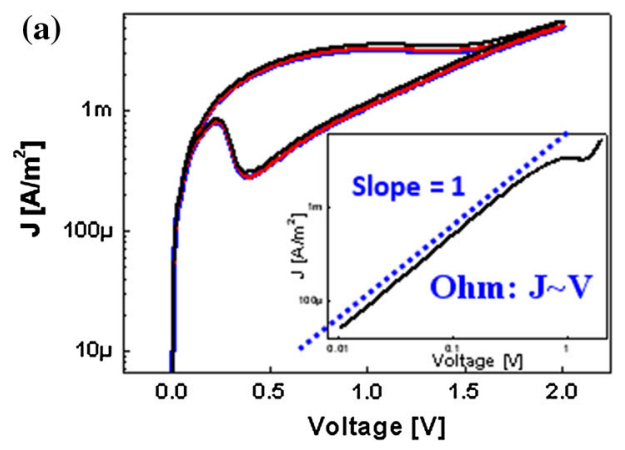

Fig. 9 Nature of electronic charge transport in the PANI skin. Semiand double (insets)-logarithmic plots of the $J-V$ curves for three successive forward-backward voltage cycles. It can be seen from the slope values of one that holes transport in the PANI coating is dominated by an Ohmic behavior in the potential range between 0 and

Reversible dimensional changes were recorded in the NPG/PANI bulk heterojunction material during successive forward-reverse voltage cycles between 0 and $2 \mathrm{~V}$, and at various sweep rates ranging from 1 to $2000 \mathrm{mV} / \mathrm{s}$. A confocal displacement sensor (IFS2401-0.4 Micro-Epsilon) was used for this purpose. Figure 10 displays typical dimensional changes as a function of the time recorded during 50 successive forward-backward potential sweeps at the sweep rate of $10 \mathrm{mV} / \mathrm{s}$, for the Au/PANI/NPG configuration. The NPG/PANI hybrid material expands during the forward sweep and contracts during the reverse process. The sign of the displacement is reversed when the actuator is connected in the NPG/PANI/Au configuration (i.e., contraction during forward sweep and expansion during backward sweep). 50 well-reproducible expansion-contraction cycles are recorded in response to 50 forwardreverse voltage cycles. The strain amplitude at the sweep

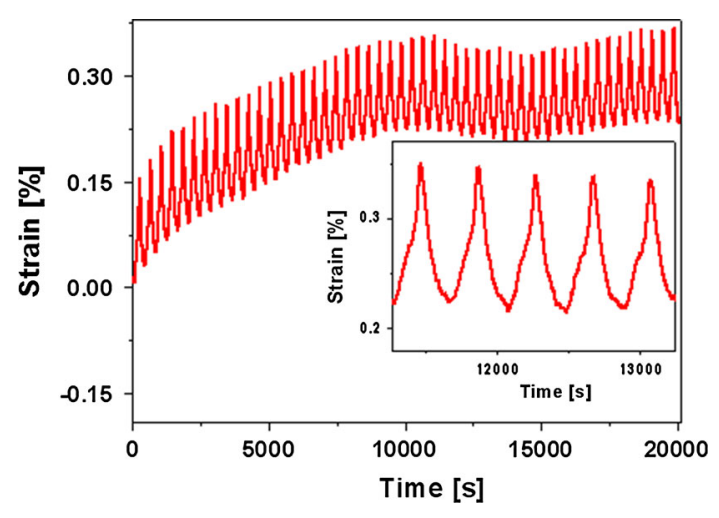

Fig. 10 Electrolyte-free actuation in NPG/PANI. 50 well-reproducible expansion-contraction cycles recorded in response to 50 successive forward-reverse $J-V$ cycles. The NPG/PANI hybrid material expands during the forward sweep and contracts during the reverse process. Reprinted from [12], with permission from the American Chemical Society

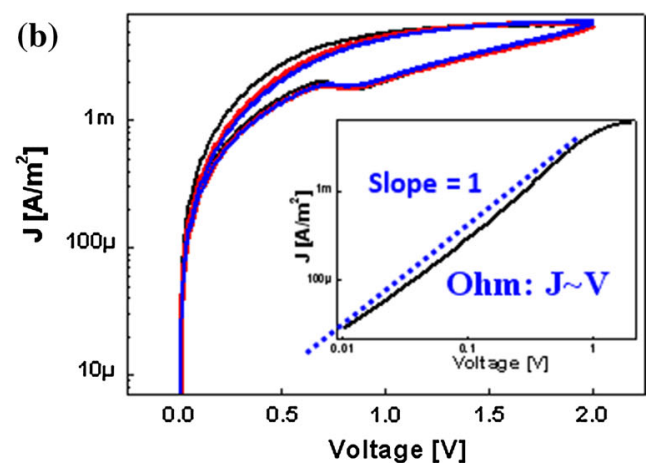

$2 \mathrm{~V}$. a Holes injection from $\mathrm{Au}$ in the $\mathrm{Au} / \mathrm{PANI} / \mathrm{NPG}$ configuration. b Holes injection from NPG in the NPG/PANI/Au configuration. Reprinted from [12], with permission from the American Chemical Society

rate of $10 \mathrm{mV} / \mathrm{s}$ is on the order of $\sim 0.15 \%$, and this is comparable to the one reported at lower sweep rates (between 0.2 and $1 \mathrm{mV} / \mathrm{s}$ ) in nanoporous metal/electrolyte composites [93].

It is emphasized that low sweep rates are required during actuation in nanoporous metals via an electrolyte; in fact dimensional changes in nanoporous metal/electrolyte composite actuators vanish at sweep rates beyond a few tens of $\mathrm{mV} / \mathrm{s}$. That behavior has two origins: (i) the low room-temperature ionic conductivity of electrolytes [100] does not favor a rapid transport of ions to the nanoporous metal/electrolyte interface; (ii) the equilibration of redox reactions involved in charged transferred at the nanoporous metal/electrolyte interface is not satisfied during fast sweep rates as highlighted in Ref. [93].

The impact of the voltage sweep rate on the performance of metallic muscles is clearly illustrated in the work of Viswanath et al. [93], who reported on a decrease of the strain amplitude in the nanoporous metal/electrolyte composite actuator from $\sim 0.14 \%$ down to $0.05 \%$ when the sweep rate is increased from $30 \mu \mathrm{V} / \mathrm{s}$ up to $1 \mathrm{mV} / \mathrm{s}$. That strain amplitude of $\sim 0.05 \%$ is achieved in $1400 \mathrm{~s}$ with the electrolyte, which corresponds to a strain rate of $3.6 \times 10^{-7} \mathrm{~s}^{-1}$. For the sake of comparison, a mammalian skeletal muscle has a strain rate of $\sim 10^{-1} \mathrm{~s}^{-1}$ [45] and is able to achieve the $0.05 \%$ strain amplitude in $5 \mathrm{~ms}$; most artificial muscles have their strain rate ranging between $\sim 10^{-3}$ and $10^{-1} \mathrm{~s}^{-1}$ [101]. In contrast to metallic muscles operating in electrolytes where dimensional changes are not present at sweep rates beyond a few tens of $\mathrm{mV} / \mathrm{s}$, reversible dimensional changes were still observed in our NPG/PANI electrolyte-free actuator at sweep rates far beyond $1 \mathrm{mV} / \mathrm{s}$ as illustrated in Fig. $11 \mathrm{a}, \mathrm{b}$, where the strain amplitudes are plotted as a function of the time and sweep rate, respectively. By setting the sweep rate at $2000 \mathrm{mV} / \mathrm{s}$, the aforementioned strain of $\sim 0.05 \%$ was 

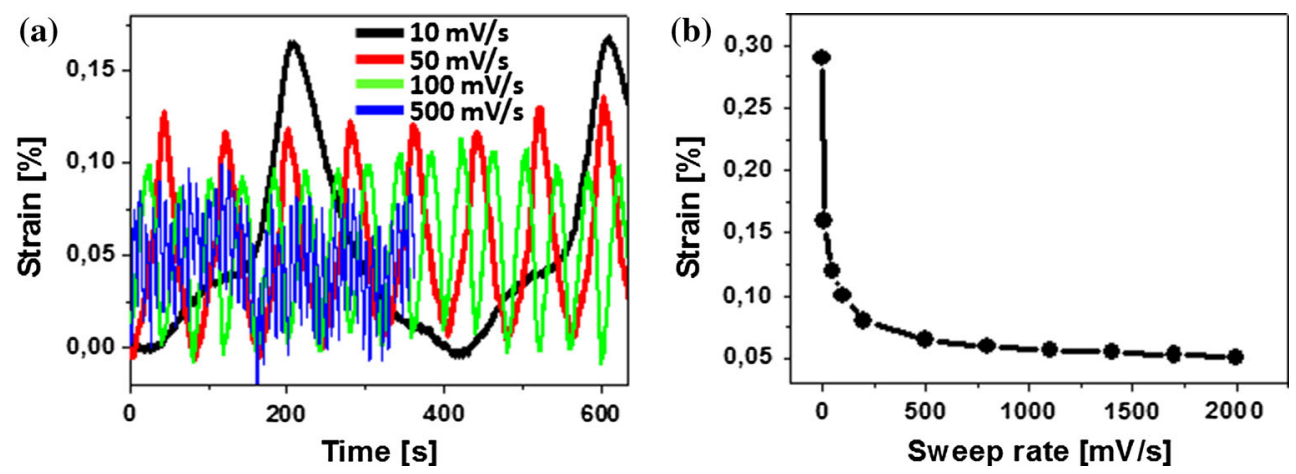

Fig. 11 Fast actuation responses. Reversible dimensional changes are recorded at various sweep rates far beyond $1 \mathrm{mV} / \mathrm{s}$ a as a function of the time and $\mathbf{b}$ as a function of the sweep rate. Reprinted from [12], with permission from the American Chemical Society (Color figure online)

achieved in our electrolyte-free actuator in $1 \mathrm{~s}$, rather than $1400 \mathrm{~s}$ as with the electrolyte [93]. This corresponds to a strain rate of $5 \times 10^{-4} \mathrm{~s}^{-1}$, which is thus about 1400 times higher than that achieved in metallic muscles via an electrolyte. These results demonstrate that by virtue of the novel electrolyte-free actuation approach, metallic muscles can operate in dry environments at high strain rates, much higher than those of common electrochemical artificial muscles.

\section{Discussion: origin of the dimensional changes in electrolyte-free actuation of metallic muscles}

Referring to the nanoporous metal/electrolyte hybrid actuator, it is well-established that dimensional changes in this system are caused by changes in the nanoporous metal surface stress, when electronic charges are injected at the nanoporous metal/electrolyte interface during ions electroadsorption. In order to preserve the mechanical equilibrium, these changes in the nanoporous metal surface stress are compensated by opposite changes in the stress state in the bulk of the ligaments [102], resulting in an overall macroscopic dimensional changes in the nanoporous metal. For our NPG/PANI hybrid material, the situation is different because no electrolyte is used during actuation. In the absence of an electrolyte, changes in the NPG surface stress as a result of electronic charges accumulation in the spacecharge region at the NPG interface are still possible, provided that an opposite space-charge builds up in the polymer coating during the voltage sweeps. However, as we have seen in the previous section, hole-transport in the PANI coating is governed by an Ohmic current (slope value of 1 in the double logarithmic plot), rather than a space-charge limited-current (slope value of 2 in the double logarithmic plot) [103]. This excludes the possibility of having changes in the surface stress of NPG as result of the build-up of a space-charge in the polymer coating.
Another possible origin of the measured dimensional changes in the NPG/PANI hybrid material points toward actuation in PANI. PANI can undergo reversible dimensional changes during electrochemical oxidation/reduction [104]. However, this option is not applicable to our electrolyte-free actuator because the electrochemical oxidation/ reduction of PANI requires an electrolyte. Second, charge carriers in conducting polymers including PANI are susceptible to induce conformational changes in the polymer chains [105-108]. This later deformation mode does not necessarily require the oxidation or reduction of the polymer [105]. Conformational changes in PANI chains can therefore be responsible for the dimensional changes in our NPG/PANI composite material provided that stresses developed in the polymer chains during these conformational changes are fully transferred to the metal. This is not likely because mechanical adhesion at metal/polymer interfaces is commonly weak [109]. In addition, the relatively small PANI content in the NPG/PANI composite material ( $\sim$ Au95(PANI)5 wt $\%)$ and the relatively low Young's modulus of PANI ( $\sim 2 \mathrm{GPa})$ [110] compared to that of the metallic ligaments $(\sim 79 \mathrm{GPa})$ lead to the conclusion that the measured strains do not come from actuation in the thin polyaniline coating.

We propose the following physical picture: as schematized in Fig. 12a, in its nonconducting state, the blue emeraldine base form of PANI consists of electrically neutral molecular chains [111]. PANI is made conducting (green emeraldine salt) by protonic acid doping or oxidative doping. During oxidative doping, an electron is removed from the pi-conjugated backbone, resulting in a free radical and a positive charge (polymeric cation) as schematized in Fig. 12b. In the case of sulfuric acid doping [111], the charge neutrality in the doped PANI is maintained by negative sulfate counter ions co-adsorbed into the polymer matrix during the doping process $[105,112]$. The schematic structure of a doped PANI chain is shown in Fig. 12b; both polymer cations and sulfate counter anions 
(a)

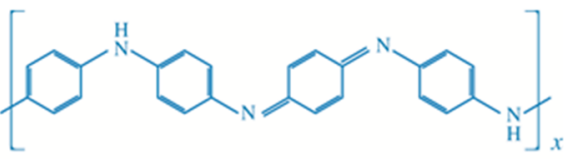

(c)

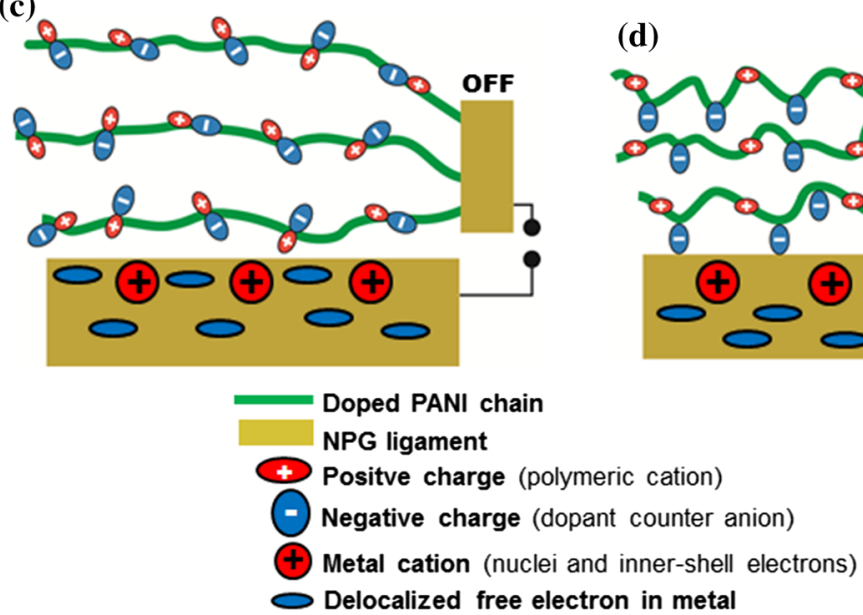

(b)

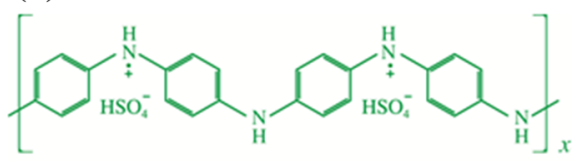

(d)

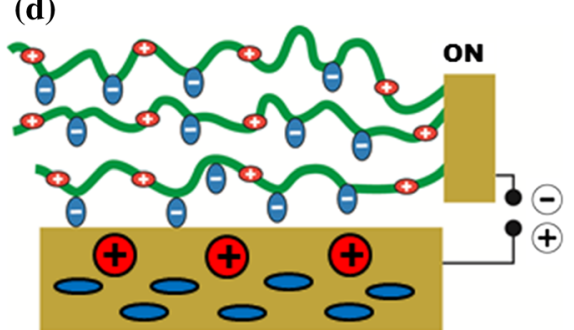

Fig. 12 Potential-induced charge redistribution at the NPG surface. a Undoped PANI (blue insulating emeraldine base). b Doped PANI (green conducting emeraldine salt). c NPG/PANI interface in the absence of an electrical potential. Both positive and negative charge carriers along the polymer chains are held together by electrostatic interaction. An initial electronic charge distribution exists at the metal

are held together by electrostatic interactions [113]. In the absence of an external electrical potential ("off" stand in Fig. 12c), polymer chains adopt shapes that favor minimal intra- and interelectrostatic interactions in the molecular chains. These shapes can be linear as reported by Lee et al. for a monolayer coating of PANI on a single Au crystal [105]. When a suitable electrical potential is applied on the hybrid actuator, e.g., in the NPG/PANI/Au configuration ("on" stand in Fig. 12d), holes are injected from the positive NPG electrode into the PANI coating. The transport of these holes across the polymer film involves the cations and free radicals on the pi-conjugate backbone [95], the positive charges on the pi-conjugated backbone become mobile during electrical conduction, whereas the negative sulfate counter ions are localized along the chains.

The total amount of negative charges in the polymer matrix, arising from the co-adsorbed sulfate anions, was estimated for a 5-nm-thick PANI coating and was found to be $\sim 3.2 \mathrm{C}$ per $\mathrm{m}^{2}$ coating, assuming that each repeating unit of PANI contributes with two sulfate anions as illustrated in Fig. 12b. This amount of charge is comparable to the quantity of electronic charge involved in dimensional changes in nanoporous metal/electrolyte hybrid actuators. During the potential sweeps, this relatively large amount of negative charge dispersed into the thin polymer matrix electrostatically interacts with the positive NPG electrode surface. d NPG/PANI interface in the presence of an electrical potential. Positive charge carriers along the polymer chains become involved in electrical conduction; localized negative charge carriers along the polymer chains electrostatically interact with the positive metal electrode, giving rise to electronic charge redistribution at the metal surface (Color figure online)

[105]. PANI molecular chains undergo conformational changes in order to bring the sulfate anions (i.e., negative charge carriers) in the proximity of the positive metal electrode; sulfate anions present in the first monolayer of PANI are eventually electroadsorbed onto the metal electrode as reported by Lee et al. and illustrated in Fig. 12d [28]. The electrical potential-induced interactions between sulfate anions and the ligaments of NPG give rise to electronic charges redistribution at the ligaments interface [114]. Typically, the delocalized free electrons in the metal move from the interface toward the bulk, leaving the metal interface with positively charged metal ions (see Fig. 12d). These metal cations consist of nuclei and inner-shell electrons of metal atoms. The delocalization of negative charges from the metal surface toward the bulk weakens the interatomic bounds between metal surface atoms, resulting in relaxation of these metal surface atoms. This gives rise to an increase in tensile stress at the surface of the ligaments. The bulk of the ligaments opposes with an increase in compressive stress in order to preserve the mechanical equilibrium [102]. Due to the high surfacearea-to-volume ratio of NPG, the dimensional changes in the ligaments result in an overall macroscopic volume change in the NPG electrode [6], which is experimentally measured during forward voltage sweeps in the NPG/ PANI/Au configuration. 
During the reverse voltage sweep where the applied electrical potential is gradually removed, electrostatic interactions between the negative sulfate ions and the positive metal electrode gradually vanish, charge redistribution takes place again at the metal interface, and the initial charge distribution is restored. This causes lesser tensile surface stress in the ligaments and accordingly a reduction of the compressive bulk counter stress [102, 114], resulting in ligaments expansion and in an overall macroscopic expansion of the NPG electrode back to its initial shape.

When the NPG/PANI hybrid actuator is connected in the configuration (Au/PANI/NPG), NPG is then used as negative electrode, and the sign of the strain is reversed (expansion during forward voltage sweeps), which suggests that in this later configuration conformational changes in the polymer chains take the negative sulfate anions away from the negative NPG electrode. Such a process will cause the delocalized electrons in the metal to move toward the metal surface, resulting in lesser tensile surface stress in NPG and, consequently, in a lesser compressive counter body stress in the bulk of the ligaments. In turn, the relaxation of the compressive stress in the bulk of the metal gives rise to a volume change.

Although the dimensional changes in the NPG/PANI hybrid actuator do not come from actuation in PANI as emphasized above, in the current understanding of the process it is believed that conformational changes in the polymer chains play an important role during actuation: (i) changes in molecular shapes of the polymer bring the sulfate anions in the proximity of the metal electrode, or take these counter anions away from the metal electrode depending on the sign of the potential applied at this electrode [28]. This process can be compared with the diffusion ions toward a metal/electrolyte interface in the case of actuation in an aqueous electrolyte. (ii) The high rate of which conducting polymers undergo conformational changes as highlighted by Yip and co-authors [107] might justify the high actuation rate recorded on the NPG/PANI composite material: rapid shape changes in polymer chains favor a fast exposure of sulfate anions to the positive NPG electrode and, consequently, rapid charge redistribution at the NPG interface. In contrast, when ions are transported through an electrolyte, a high actuation rate is hampered because of the low ionic conductivity of electrolytes [100].

The work density $W=1 / 2 Y \varepsilon^{2}$ of the NPG/PANI actuator $\left(\sim 113 \mathrm{~kJ} / \mathrm{m}^{3}\right)$, is comparable to the $\sim 130 \mathrm{~kJ} / \mathrm{m}^{3}$ achieved in piezoceramics [4] and $90 \mathrm{~kJ} / \mathrm{m}^{3}$ reported for the nanoporous metal/electrolyte actuator in Ref. [8]. In the above expression, $W, Y$, and $\varepsilon$ represent the volume work density, effective Young's modulus, and maximum strain amplitude, respectively [44, 115]. Although the work density is the standard measure for the mechanical performance of artificial muscles, it is pointed out that a high value of $\mathrm{W}$ does not necessarily mean that the corresponding actuation material is suitable for every application. In fact, each actuation material satisfies only specific applications depending on how $\mathrm{Y}$ and $\varepsilon$ are combined: materials such as electroactive polymers can produce large actuation strokes $(\varepsilon \sim 4.5 \%)$, but they are weak $(Y \sim 1.1 \mathrm{GPa})$; other like piezoceramics are strong $(Y \sim 64 \mathrm{GPa})$ but their strain amplitudes are restricted to $\sim 0.2 \%$. Metallic muscles are unique for a number of reasons, but none-more-so than in the sense that they can achieve a wide range of strengths as depicted by the effective Young's modulus of NPG, which is tunable from $\sim 5$ to $\sim 45 \mathrm{GPa}$ through manipulation of the ligaments' size [116]. Additionally, they can also be designed to achieve a wide window of strain amplitudes ranging from the standard value of $\sim 0.1 \%$ up to large strains of $\sim 1.3 \%$ in binary nanoporous alloys [8].

As regards the small volumetric strain of about $0.1 \%$, we have designed a new type of nanoporous gold architecture consisting of a two-microscopic length scale structure and details are presented in [44]. The nanoporous gold with the two-microscopic length scale structure consists of stacked gold layers with submicrometer thicknesses; in turn each of these layers displays nanoporosity through its entire bulk. This two-length scale structure strongly enhances the stain amplitude in metallic muscles up to $6 \%$, compared to the standard strain of $\sim 0.1 \%$ achieved in nanoporous metals with one-microscopic length scale structure (i.e., with uniform porous structure). The ratio between the work density of NPG actuator with a dual-microscopic length scale (volumetric strain $6 \%$ ) and that of NPG actuator with a one-length scale porous morphology (volumetric strain $0.3 \%$ ) was found to be $\sim 215$. It is concluded that the relatively low effective Young's modulus of NPG with layered structure (compared to that of NPG with a uniform porous morphology) is largely compensated by the giant strain amplitudes. The large strains in NPG with layered structure give rise to an enhancement of the work density with at least two orders of magnitude.

Recently, various alternatives for achieving large displacements in actuation materials have been investigated [47], and several ideas were proposed for the displacement amplification including cantilever systems, hydraulic-piston devices, and piezoelectric motors. These techniques however are not always appropriate for microscale applications. Kramer et al. have achieved large relative displacements during cantilever bending experiments [9], up to $\sim 3 \mathrm{~mm}$ over a length of $\sim 35-40 \mathrm{~mm}$, by using a nanoporous metal strip to design a $40 \mathrm{~mm}$-long bilayer strips. One advantage of the actuation mechanism associated to the layered structure we developed is the possibility 
to achieve comparable large relative displacements at smaller scales: displacements up to $\sim 4 \mu \mathrm{m}$ can be achieved over a thickness of $\sim 70 \mu \mathrm{m}$. Furthermore, the multilength scale layered nanoporous systems operate at low voltages compared to common artificial muscles. Exploiting a polymer skin augmentation of the muscle for actuation, as we have demonstrated, is expected to stimulate the development of metallic muscles into a new class of actuation materials that operate at low voltages and combine large strain amplitudes with high stiffness and strength.

\section{Summary and outlook for next generation applications of nanoporous metals}

In conclusion, although metal nanofoams share many properties with their macrofoam counterparts, they have many applications beyond those of macrofoams. One promising application corresponds to metallic muscles based on nanoporous metals with high surface-area-tovolume ratios. For that specific application, we have demonstrated a new electrolyte-free approach to generate work from metallic muscles by exploiting a nanoporous metal/polymer interface rather than the common nanoporous metal/liquid electrolyte interface. In this actuation concept, a doped polymer coating is grown onto the ligaments of a nanoporous metal, and dopant counter ions present in the polymer coating matrix are exploited to modulate the electronic charge distribution at the nanoporous metal surface, resulting in surface stress changes and dimensional changes in the nanoporous metal. With this actuation approach, many of the drawbacks encountered in metallic muscles operating in aqueous electrolytes have been circumvented. In particular, the electrolyte-free actuator consists of a single-component hybrid material, in contrast to the three-component configuration required in nanoporous metal/electrolyte composite actuators; the nanoporous metal/polymer hybrid actuator is an all-solidstate device, like piezoceramic actuators, and its actuation rate is about three orders of magnitude higher than that of metallic muscles operating in aqueous electrolytes.

An interesting observation is that a thin polymer coating grown onto the metallic ligaments of nanoporous gold can be exploited to add a new functionality to nanoporous metals operating as electrochemical actuators. For example, a metallic muscle becomes a smart material because in addition to its reversible dimensional changes, it also undergoes a reversible change in color. This combination of electromechanical and optical changes could open the door to new applications in artificial muscles. A straightforward application includes a metallic muscle that can give feedback on the progress on its work simply by changing its color [117, 118]. An interesting and rather new development in this field of actuation was recently published by Shih and co-authors [119] making an actuator made from botanic epidermal cells. This soft actuator changes its actuation direction by simply changing the magnitude of the applied voltage. In fact, the single-layered, latticed microstructure of onion epidermal cells after acid treatment became elastic and could simultaneously stretch and bend when an electric field was applied.

The exciting outlook for nanoporous metallic systems is not limited to the fields of sensors and actuators, however, where electrical or electrochemical energy is converted into mechanical work. The use of nanoporous metals and nanostructured materials in general [120] in other energyrelated applications has recently been demonstrated. For example, there is currently much interest in the sustainable production of hydrogen fuel by the decomposition of water-based solutions into hydrogen and oxygen as the only products using alkaline electrolyzers. Interestingly, state-of-the-art oxygen evolution catalysts are increasingly grown on macroporous nickel foams, in order to improve the catalytic activity of these anode electrolyzers [121, 122]. We have recently shown that catalytic activities toward oxygen evolution can be significantly enhanced if nanofoam catalysts are directly used as electrolyzer anodes [123], instead macroporous foams. In general, unsupported nonprecious metals oxygen-evolving catalysts require at least $\sim 350 \mathrm{mV}$ overpotential to oxidize water with a current density of $10 \mathrm{~mA} \mathrm{~cm}{ }^{-2}$ in $1 \mathrm{M}$ alkaline solution [124]. In our work, we have recently found a robust ultrafine mesoporous NiFe-based oxygen evolution catalyst made by partial removal of $\mathrm{Fe}$ and $\mathrm{Mn}$ from $\mathrm{Ni}-\mathrm{Fe}-\mathrm{Mn}$ parent alloys [123]. The fine microstructure of our mesoporous NiFe-based oxygen evolution catalyst is shown at different magnifications in Fig. 13 [123]. Ligament and pore sizes are of the order of $10 \mathrm{~nm}$. In $0.5 \mathrm{M} \mathrm{KOH}$, only $\sim 200 \mathrm{mV}$ overpotential was required to oxidize water with a current density of $10 \mathrm{~mA} \mathrm{~cm}^{-2}$. In $1 \mathrm{M} \mathrm{KOH}$, our material exhibits a catalytic activity toward water oxidation of $500 \mathrm{~mA} \mathrm{~cm}^{-2}$ at $360 \mathrm{mV}$ overpotential and is stable for over 11 days. This exceptional performance is attributed to a combination of the small size of ligaments and pores in our mesoporous catalyst $(\sim 10 \mathrm{~nm})$, the high BET surface area that results from those sites $\left(43 \mathrm{~m}^{2} \mathrm{~g}^{-1}\right)$, and therefore the high density of oxygen-evolving catalytic sites per unit mass. In addition, the open porosity facilitates effective mass transfer at the catalyst/electrolyte interface, and the high electrical conductivity of the mesoporous catalyst allows for effective current flow. Such a robust mesoporous catalyst is attractive for alkaline electrolyzers where waterbased solutions are decomposed into hydrogen and oxygen as the only products. 

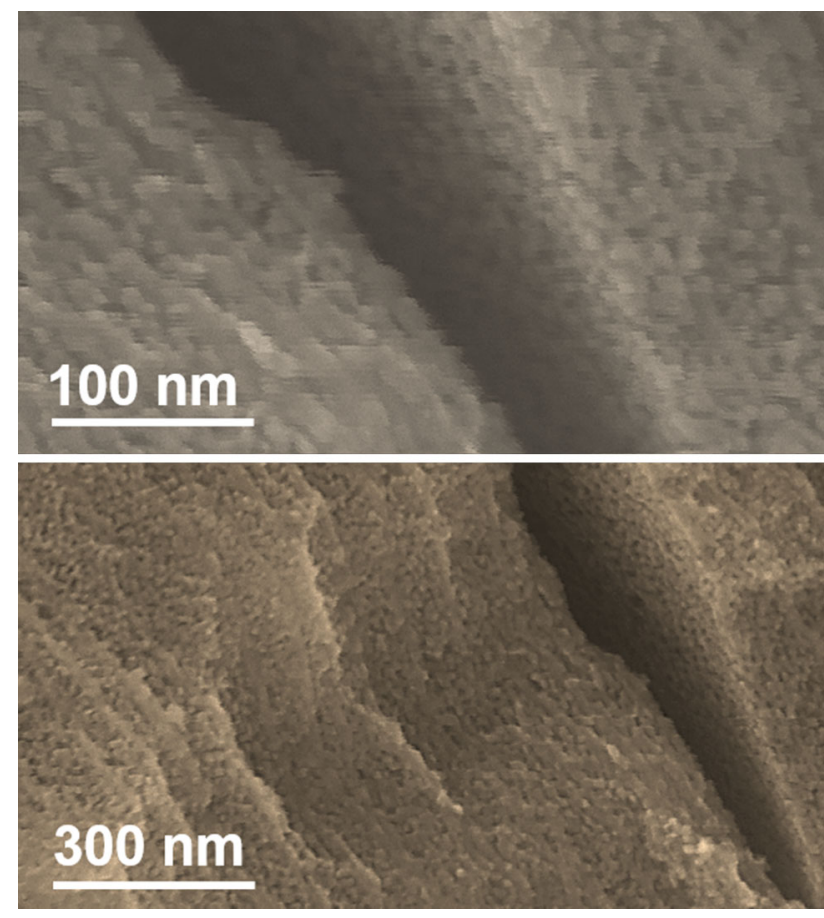

Fig. 13 Mesoporous NiFe-based oxygen evolution catalyst at different magnifications. Ligament and pore sizes are of the order of $10 \mathrm{~nm}$

Another promising application where nanoporous metallic system could have a significant impact is Li-ion and Na-ion batteries, where electrical energy is stored in the form of chemical energy. Porosity evolution in nanoporous tin (NP-Sn) during selective removal of $\mathrm{Li}$ from $\mathrm{Li}-$ Sn alloys was recently investigated by Chen and Sieradzki [125]. The ligaments in their NP-Sn exhibit an interpenetrating 'nanowire' type morphology, similar to that of common nanoporous metals. We have recently reported on the synthesis of NP-Sn powder with a unique granular-like ligament morphology using $\mathrm{Sn}-\mathrm{Mg}$ binary alloys as precursor and selectively removing the sacrificial Mg by freecorrosion dealloying. The typical microstructure of our NPSn powder is shown in Fig. 14a. [126-128]. In general, mechanically stable monolithic nanoporous metals are made by limiting the content of the sacrificial component in the parent alloys between 60 and 70 at.\%. However, for applications involving $\mathrm{Li}$-ion or $\mathrm{Na}$-ion battery electrode slurries, NP-Sn powder (instead of monolithic NP-Sn) is desirable. The high magnification SEM of typical powder particles indicate that they are porous (see Fig. 14b). While the porous architecture is disordered like in common nanoporous metals, the ligaments exhibit granular-like morphology (see Fig. 14c), rather than an interpenetrating 'nanowire' type morphology. The ligament diameter exhibits a broad distribution, in the range between $\sim 100$ and $\sim 200 \mathrm{~nm}$ (Fig. 2c). Further magnification of these ligaments shows that they consist of clustered $\mathrm{Sn}$ nanoparticles with size in the sub-10-nm range (Not shown). These small feature sizes give rise to a relatively high BET surface area $\left(\sim 19 \mathrm{~m}^{2} \mathrm{~g}^{-1}\right)$ in our NP-Sn powder. Due to its unique granular-like ligament morphology, the NP-Sn powder exhibits stable cycling as anodes in combination with both lithium and sodium. Figure $14 \mathrm{~d}$ shows an example of a galvanostatic curve obtained using $\mathrm{Li}^{+}$; good stability over a few hundred cycles can be achieved [126-128].

Overall we may conclude that metallic nanofoams sit at the centrepoint of a myriad of engineering disciplines, enabling a variety of applications because of their chemical and structural diversity. In this contribution, we have
Fig. 14 Nanoporous Sn (NP$\mathrm{Sn})$ as anode material for the next generation Li-ion battery. a As-synthesized fine NP-Sn powder dispersed on a carbon substrate. The powder particles have random shapes and random size in the sub-10- $\mu \mathrm{m}$ ranges. b High magnification SEM showing that the powder particles are porous. c The ligaments exhibit granular-like morphology. TEM analysis reveals that these granular ligaments are in turn porous (not shown). d Examples of galvanostatic curves obtained using $\mathrm{Li}^{+}$. Good stability over a few hundred cycles can be achieved
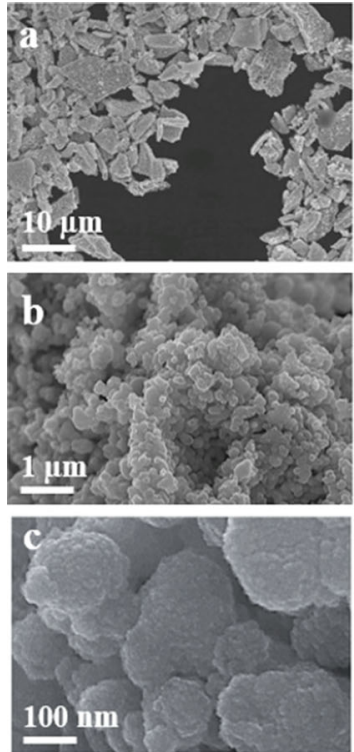

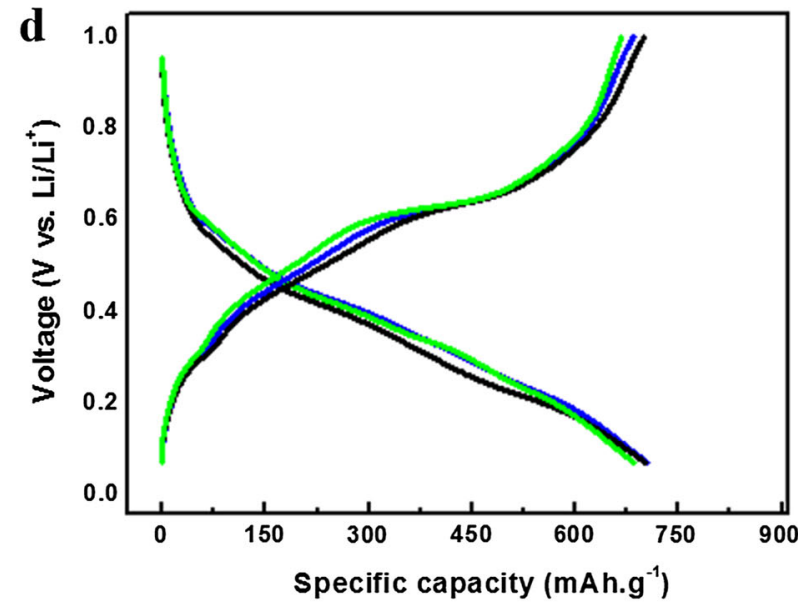


highlighted mainly the 'metallic muscle' performance, and as far as functional properties are concerned, modern actuating materials-i.e., materials that have the capacity for controlled deformation under an applied electric current-nanoporous metals make ideal candidates for such roles. Actuation in nanoporous metals is enabled by the fact that injection of charge into a metal causes a change of surface charge, which is amplified due to the high surfaceto-volume ratio present in a nanoporous metal; this ultimately leads to measurable deformation. Clearly as porous materials, these systems display excellent surface-area-tovolume ratios and attractive commercial properties such as reasonable low-cost production. As nanostructured materials, they also offer many properties often sought-out for potential applications: good electrical and thermal conductivity, strong capacity as catalyst and catalyst carrier, and potentially exploitable optical properties, to name just a few. As metals, they boast the robust mechanical properties required of a structural material: strength, impact resistance, and resistance to aging $[129,130]$. In particular, the exploitation of nanoporous metals in energy-related applications such as hydrogen fuel production and batteries opens novel avenues for fundamental and applied materials research that may result in many new publications during the next 50 years in the Journal of Materials Science.

Acknowledgements The authors are thankful to the Netherlands Organization for Scientific Research (NWO-the Hague, Mozarek Grant 2008 BOO Dossiernr: 017.005.026 and the Rubicon Grant Dossiernr: 680-50-1214) and the Zernike Institute for Advanced Materials, University of Groningen, the Netherlands. Fruitful discussions with Patrick Onck and the testing of NP-Sn by John Cook are gratefully acknowledged.

\section{Compliance with ethical standards}

Conflict of Interest The authors declare that they have no conflict of interest.

Open Access This article is distributed under the terms of the Creative Commons Attribution 4.0 International License (http://crea tivecommons.org/licenses/by/4.0/), which permits unrestricted use, distribution, and reproduction in any medium, provided you give appropriate credit to the original author(s) and the source, provide a link to the Creative Commons license, and indicate if changes were made.

\section{References}

1. Schaller RR (1997) Moore's law: past, present, and future. Spectr IEEE 34(52):59

2. Hunter IW, Lafontaine SA (1992) Comparison of muscle with artificial actuators. In: Solid-state sensor and actuator workshop, 5th technical digest., IEEE, pp 178-185

3. Momosaki E, Kogure S (1982) The application of piezoelectricity to watches. Ferroelectrics 40:203-216
4. Jin HJ, Wang XL, Parida S, Wang K, Seo M, Weissmüller J (2010) Nanoporous Au-Pt alloys as large strain electrochemical actuators. Nano Lett 10:187-194. doi:10.1021/n1903262b

5. Mirfakhrai T, Madden JDW, Baughman RH (2007) Polymer artificial muscles. Mater Today 10:30-38. doi:10.1016/S13697021(07)70048-2

6. Li DB, Paxton WF, Baughman RH, Huang TJ, Stoddart JF, Weiss PS (2009) Molecular, supramolecular, and macromolecular motors and artificial muscles. MRS Bull 34:671-681. doi: $10.1557 / \mathrm{mrs} 2009.179$

7. Gleiter H, Weissmüller J, Wollersheim O, Würshum R (2009) Nanocrystalline materials: a way to solids with tunable electronic structures and properties ? Acta Mater 49:737-745. doi:10.1016/S1359-6454(00)00221-4

8. Weissmüller J, Viswanath RN, Kramer D, Zimmer P, Würschum R, Gleiter H (2003) Charge-induced reversible strain in a metal. Science 300:312-315. doi:10.1126/science.1081024

9. Kramer D, Viswanath RN, Weissmuller J (2004) Surface-stress induced macroscopic bending of nanoporous gold cantilevers. Nano Lett 4:793-796. doi:10.1021/n1049927d

10. Biener J, Hodge AM, Hamza AV, Hsiung LM, Satcher JH (2005) Nanoporous Au: a high yield strength material. J Appl Phys 97:024301-1-024301-4. doi:10.1063/1.1832742

11. Balk TJ, Eberl C, Sun Y, Hemker KJ, Gianola DS (2009) Tensile and compressive microspecimen testing of bulk nanoporous gold. JOM 61:26-31. doi:10.1007/s11837-009-0176-6

12. Detsi E, Onck P, De Hosson JTM (2013) Metallic muscles at work: High rate actuation in nanoporous gold/polyaniline composites. ACS Nano 7:4299-4306. doi:10.1021/nn400803x

13. Biener J, Hodge AM, Hayes JR, Volkert CA, Zepeda-Ruiz LA, Hamza AV, Abraham FF (2006) Size effects on the mechanical behavior of nanoporous Au. Nano Lett 6:2379-2382. doi:10. 1021/n1061978i

14. Xia R, Xu C, Wu W, Li X, Feng XQ, Ding Y (2009) Microtensile tests of mechanical properties of nanoporous $\mathrm{Au}$ thin Films. J Mater Sci 44:4728-4733. doi:10.1007/s10853-0093731-1

15. Li R, Sieradzki K (1992) Ductile-brittle transition in random porous Au. Phys Rev Lett 68:1168-1171. doi:10.1103/Phys RevLett.68.1168

16. Biener J, Hodge AM, Hamza AV (2005) Microscopic failure behavior of nanoporous gold. Appl Phys Lett 87:121908. doi:10. 1063/1.2051791

17. Volkert CA, Lilleodden ET, Kramer D, Weissmüler J (2006) Approaching the theoretical strength in nanoporous Au. Appl Phys Lett 89:061920. doi:10.1063/1.1832742

18. Gibson LJ, Ashby MF (1997) Cellular solids: structure and properties, 2nd edn. Cambridge University Press, Cambridge

19. Punzhin S, Detsi E, Kuzmin A, De Hosson JTM (2014) Deformation of nanoporous nanopillars by ion beam-induced bending. J Mater Sci 49:5598-5605. doi:10.1007/s10853-0148269-1

20. Amsterdam E, De Vries JHB, De Hosson JTM, Onck PR (2008) The influence of strain-induced damage on the mechanical response of open-cell aluminum foam. Acta Mater 56:609-618. doi:10.1016/j.actamat.2007.10.034

21. Michielsen K, De Raedt H, De Hosson JTM (2002) Aspects of integral-geometry. Adv Imaging Electron Phys 125:119-195

22. Amsterdam E, Onck PR, De Hosson JTM (2005) Fracture and microstructure of open cell aluminum foam. J Mater Sci 40:5813-5819. doi:10.1007/s10853-005-4995-8

23. Amsterdam E, Goodall R, Mortensen A, Onck PR, De Hosson JTM (2008) Fracture behavior of low-density replicated aluminum alloy foams. Mater Sci Eng A 496:376-382. doi:10. 1016/j.msea.2008.05.036 
24. Amsterdam E, De Hosson JTM, Onck PR (2008) On the plastic collapse stress of open-cell aluminum foam. Scr Mater 59:653-656. doi:10.1016/j.scriptamat.2008.05.025

25. Amsterdam E, Van Hoorn H, De Hosson JTM, Onck PR (2008) The influence of cell shape anisotropy on the tensile behavior of open cell aluminum foam. Adv Eng Mater 10:877-881. doi:10. 1002/adem.200800128

26. Wittstock A, Zielasek V, Biener J, Friend CM, Baumer M (2010) Nanoporous gold catalysts for selective gas-phase oxidative coupling of methanol at low temperature. Science 327:319-322. doi:10.1126/science.1183591

27. Nagle LC, Rohan JF (2011) Nanoporous gold anode catalyst for direct borohydride fuel cell. Int J Hydrog Energy 36:10319-10326. doi:10.1016/j.ijhydene.2010.09.077

28. Lang XY, Yuan HT, Iwasa Y, Chen MW (2011) Three-dimensional nanoporous gold for electrochemical supercapacitors. Scr Mater 64:923-926. doi:10.1016/j.scriptamat.2011.01.038

29. Gittard SD, Pierson BE, Ha CM, Wu C-AM, Narayan RJ, Robinson DB (2010) Supercapacitive transport of pharmacologic agents using nanoporous gold electrodes. Biotechnol $\mathrm{J}$ 5:192-200. doi:10.1002/biot.200900250

30. Yavuz MS, Cheng Y, Chen J, Cobley CM, Zhang Q, Rycenga M, Xie J, Kim C, Song KH, Schwartz AG, Wang LV, Xia Y (2009) Gold nanocages covered by smart polymers for controlled release with near-infrared light. Nat Mater 8:935-939. doi:10.1038/nmat2564

31. Au L, Zheng D, Zhou F, Li Z-Y, Li X, Xia Y (2008) A quantitative study on the photothermal effect of immuno gold nanocages targeted to breast cancer cells. ACS Nano 2:1645-1652. doi:10.1021/nn800370j

32. Chuan C; Ngan AHW (2015) Reversible electrochemical actuation of metallic nanohoneycombs induced by pseudocapacitive redox processes. ACS Nano 9:3984-3995. doi:10.1021/nn507466n

33. Biener J, Wittstock A, Baumann TF, Weissmuller J, Baumer M, Hamza AV (2009) Surface chemistry in nanoscale materials. Materials 2:2404-2428. doi:10.3390/ma2042404

34. Kwan KW, Gao P, Martin CR, Ngan AHW (2015) Electrical bending actuation of gold-films with nanotextured surfaces. Appl Phys Lett 106:023701. doi:10.1063/1.4905676

35. Cheng C, Ngan AHW (2013) Charge-induced reversible bending in nanoporous alumina-aluminum composite. Appl Phys Lett 102:213119-2131122. doi:10.1063/1.4808212

36. Detsi E, Chen ZG, Vellinga WP, Onck PR, De Hosson JTM (2012) Actuating and sensing properties of nanoporous gold. J Nanosc Nanotechnol 11:4951-4955. doi:10.1166/jnn.2012. 4882

37. Detsi E, Chen ZG, Vellinga WP, Onck PR, De Hosson JTM (2011) Reversible strain by physisorption in nanoporous gold. Appl Phys Lett 99:083104. doi:10.1063/1.3625926

38. Jayachandran KP, Guedes JM, Rodrigues HC (2011) Ferroelectric materials for piezoelectric actuators by optimal design. Acta Mater 59:3770-3778. doi:10.1016/j.actamat.2011.02.005

39. Ibach H (1997) The role of surface stress in reconstruction, epitaxial growth and stabilization of mesoscopic structures. Surf Sci Rep 29:193-263. doi:10.1016/S0167-5729(97)00010-1

40. Needs RJ, Godfrey MJ, Mansfield M (1991) Theory of surface stress and surface reconstruction. Surf Sci 242:215-221. doi:10. 1016/0039-6028(91)90269-X

41. Salomons E, Griessen R, De Groot DG, Magerl A (1988) Surface-tension and subsurface sites of metallic nanocrystals determined by $\mathrm{H}$-absorption. Europhys Lett 5:449-454

42. Jin HJ, Weissmüller J (2010) Bulk nanoporous metal for actuation. Adv Eng Mater 12:714-723. doi:10.1002/adem. 200900329

43. Saane SSR, Mangipudi KR, Loos KU, DecHosson JTM, Onck PR (2014) Multiscale modeling of charge-induced deformation of nanoporous gold structures. J Mech Phys Sol 66:1-15. doi:10. 1016/j.jmps.2014.01.007

44. Detsi E, Punzhin S, Rao J, Onck PR, De Hosson JTM (2012) Enhanced strain in functional nanoporous gold with a dual microscopic length scale structure. ACS Nano 6:3734-3744. doi:10.1021/nn300179n

45. Baughman RH (2003) Muscles made from metal. Science 300:268-269. doi:10.1126/science.1082270

46. Zhang J, Liu P, Ma H, Ding Y (2007) Nanostructured porous gold for methanol electro-oxidation. J Phys Chem C 111:10382. doi:10.1021/jp072333p

47. Conway NJ, Traina ZJ, Kim SG (2007) A strain amplifying piezoelectric MEMS actuator. J Micromech Microeng 17:781-787. doi:10.1088/0960-1317/17/4/015

48. Erlebacher Aziz MJ, Karma A, Dimitrov N, Sieradzki K (2001) Evolution of nanoporosity in dealloying. Nature 410:450. doi: $10.1038 / 35068529$

49. Kimling J, Maier M, Okenve B, Kotaidis V, Ballot H, Plech A (2006) Turkevich method for gold nanoparticle synthesis revisited. J Phys Chem B 110:15700-15707. doi:10.1021/ jp061667w

50. Detsi Van, de Schootbrugge M, Punzhin S, Onck PR, De Hosson JTM (2011) On tuning the morphology of nanoporous gold. Scr Mater 64:319-322. doi:10.1016/j.scriptamat.2010.10.023

51. Hodge A, Biener J, Hayes J, Bythrow P, Volkert C, Hamza A (2007) Scaling equation for yield strength of nanoporous opencell foams. Acta Mater 55:1343. doi:10.1016/j.actamat.2006.09. 038

52. Detsi E, Selles MS, Onck PR, De Hosson JTM (2013) Nanoporous silver as electrochemical actuator. Scr Mater 69:195-198. doi:10.1016/j.scriptamat.2013.04.003

53. Sun L, Chien CL, Searson PC (2004) Fabrication of nanoporous nickel by electrochemical dealloying. Chem Mater 16:3125-3129. doi:10.1021/cm0497881

54. Wang XG, Qi Z, Zhao CC, Wang WM, Zhang ZH (2009) Influence of alloy composition and dealloying solution on the formation and microstructure of monolithic nanoporous silver through chemical dealloying of $\mathrm{Al}-\mathrm{Ag}$ alloys. J Phys Chem C113:13139-13150. doi:10.1021/jp902490u

55. Li W-C, Balk TJ (2010) Achieving finer pores and ligaments in nanoporous palladium-nickel thin films. Scr Mater 62:167-169. doi:10.1016/j.scriptamat.2009.10.009

56. Sun Y, Burger SA, Balk TJ (2014) Controlled ligament coarsening in nanoporous gold by annealing in vacuum versus nitrogen. Philos Mag 94:1001-1011. doi:10.1080/14786435. 2013.876113

57. Wang L, Balk TJ (2014) Synthesis of nanoporous nickel thin films from various precursors. Philos Mag Let 94:573-581. doi: $10.1080 / 09500839.2014 .944600$

58. Kim MS, Nishikawa H (2013) Fabrication of nanoporous silver and microstructural change during dealloying of melt-spun Al20at.\% Ag in hydrochloric acid. J Mater Sci 48:5645-5652. doi:10.1007/s10853-013-7360-3

59. Wang J, Xia R, Zhu J, Ding Y, Zhang X, Chen Y (2012) Effect of thermal coarsening on the thermal conductivity of nanoporous gold. J Mater Sci 47:5013-5018. doi:10.1007/s10853-0126377-3

60. Li ZQ, Li BQ, Qin ZX, Lu X (2010) Fabrication of porous Ag by dealloying of $\mathrm{Ag}-\mathrm{Zn}$ alloys in $\mathrm{H}_{2} \mathrm{SO}_{4}$ solution. $\mathrm{J}$ Mater Sci 45:6494-6497. doi:10.1007/s10853-010-4737-4

61. Zinchenko O, De Raedt HA, Detsi E, Onck PR, De Hosson JTM (2013) Nanoporous gold formation by dealloying: a metropolis Monte Carlo study. Comput Phys Commun 184:1562-1569. doi:10.1016/j.cpc.2013.02.004

62. Van Bremen R, Ribas Gomes D, de Jeer LTH, Ocelík, De Hosson JTM (2015). On the optimum resolution of 
transmission-electron backscattered diffraction (t-EBSD). Ultramicroscopy (submitted)

63. Keller R, Geiss RH (2012) Transmission EBSD from $10 \mathrm{~nm}$ domains in a scanning electron microscope. $\mathrm{J}$ Microsc 245:245-251. doi:10.1111/j.1365-2818.2011.03566.x

64. Trimby PW (2012) Orientation mapping of nanostructured materials using transmission Kikuchi diffraction in the scanning electron microscope. Ultramicroscopy 120:16-24. doi:10.1016/ j.ultramic.2012.06.004

65. Brodusch N, Demers H, Trudeau M, Gauvin R (2013) Acquisition parameters optimization of a transmission electron forward scatter diffraction system in a cold-field emission scanning electron microscope for nanomaterials characterization. Scanning 35:375-386. doi:10.1002/sca.21078

66. Geiss R, Keller R, Sitzman S, Rice P (2011) New method of transmission electron diffraction to characterize nanomaterials in the SEM. Microsc Microanal 17:386-387. doi:10.1017/ S1431927611002807

67. de Jeer LTH, Ribas Gomes D, Nijholt J, Ocelik V, De Hosson JTM (2015) Formation of nanoporous gold studied by transmission kikuchi diffraction. J Microsc Microanal, submitted 2015

68. Hayes JR, Hodge AM, Biener J, Hamza AV, Sieradzki K (2006) Monolithic nanoporous copper by dealloying $\mathrm{Mn}-\mathrm{Cu}$. J Mater Res 21:2611-2616. doi:10.1557/jmr.2006.0322

69. Min US, Li JCM (1994) The microstructure and dealloying kinetics of a $\mathrm{Cu}-\mathrm{Mn}$ alloy. J Mater Res 9:2878-2883. doi:10. 1557/JMR.1994.2878

70. Foresi JS, Villeneuve PR, Ferrera J, Thoen ER, Steinmeyer G, Fan S, Joannopoulos JD, Kimerling LC, Smith HI, Ippen EP (1997) Photonic-bandgap microcavities in optical waveguides. Nature 390:143-145. doi:10.1038/36514

71. Palasantzas G, De Hosson JTM, Michielsen KFL, Stavenga DG (2005) Optical properties and wettability of nanostructured biomaterials: moth eyes, lotus leaves, and insect wings. Handbook of nanostructured bio-materials and their applications in nanobiotechnology (Chap. 7). American Science Publications, Valencia, pp 274-301

72. Li X, Tao F, Jiang Y, Xu Z (2007) 3-D Ordered macroporous cuprous oxide: fabrication, optical, and photoelectrochemical properties. J Colloid Interface Sci 308:460-465. doi:10.1016/j. jcis.2006.12.044

73. Soni K, Rana BS, Sinha AK, Bhaumik A, Nandi M, Kumar M, Dhar GM (2009) 3-D ordered mesoporous KIT-6 support for effective hydrodesulfurization catalysts. Appl Catal B 90:55-63. doi:10.1016/j.apcatb.2009.02.010

74. Meng Y, Gu D, Zhang F, Shi Y, Yang H, Li Z, Yu C, Tu B, Zhao D (2005) Ordered mesoporous polymers and homologous carbon frameworks: amphiphilic surfactant templating and direct transformation. Angew Chem 117:7215-7221. doi:10. 1002/anie.200501561

75. Fang TH, Wang TH, Kang SH (2019) Nanomechanical and surface behavior of polydimethylsiloxane filled nanoporous anodic alumina. J Mater Sci 44:1588-1593. doi:10.1007/ s10853-008-3232-7

76. Yu H, Wang D, Han MY (2007) Top-down solid-phase fabrication of nanoporous cadmium oxide architectures. J Am Chem Soc 2007:2333-2337. doi:10.1021/ja066884p

77. Garrigue P, Delville MH, Labrugere C, Cloutet E, Kulesza PJ, Morand JP, Kuhn A (2004) Top-down approach for the preparation of colloidal carbon nanoparticles. Chem Mater 16:2984-2986. doi:10.1021/cm049685i

78. Jeon HJ, Kim KH, Baek YK, Kim DW, Jung HT (2010) New top-down approach for fabricating high-aspect-ratio complex nanostructures with $10 \mathrm{~nm}$ scale features. Nano Lett 10:3604-3610. doi:10.1021/nl1025776
79. Van Eerdenbrugh B, Van den Mooter G, Augustijns P (2008) Top-down production of drug nanocrystals: nanosuspension stabilization, miniaturization and transformation into solid products. Int J Pharm 364:64-75. doi:10.1016/j.ijpharm.2008. 07.023

80. Koch CC (2003) Top-down synthesis of nanostructured materials: mechanical and thermal processing methods. Rev Adv Mater Sci 5:91-99

81. Yan Y, Hu Z, Zhao Z, Sun T, Dong S, Li X (2010) Top-down nanomechanical machining of three-dimensional nanostructures by atomic force microscopy. Small 6:724-728. doi:10.1002/ smll.200901947

82. Vukovic I, Punzhin S, Vukovic Z, Onck P, De Hosson JTM, ten Brinke G, Loos K (2011) Supramolecular route to well-ordered metal nanofoams. ACS Nano 5:6339-6348. doi:10.1021/nn201421y

83. Hakamada M, Mabuchi M (2007) Mechanical strength of nanoporous gold fabricated by dealloying. Scr Mater 56:1003-1006

84. Hodge AM, Hayes JR, Caro JA, Biener J, Hamza AV (2006) Characterization and mechanical behavior of nanoporous gold. Adv Eng Mater 8:853-857

85. Dinh Ngô Bao-Nam, Stukowski A, Mameka N, Markmann J, Albe K, Weissmüler J (2015) Anomalous compliance and early yielding of nanoporous gold. Acta Mater 93:144-155

86. Detsi E, De Jong E, Zinchenko A, Vukovic Z, Vukovic I, Punzhin S, Loos K, Ten Brinke G, De Raedt HA, Onck PR, De Hosson JTM (2011) On the specific surface area of nanoporous materials. Acta Mater 59:7488-7497. doi:10.1016/j.actamat. 2011.08.025

87. Tan YH, Davis JA, Fujikawa K, Ganesh NV, Demchenko AV, Stine KJ (2012) Surface area and pore size characteristics of nanoporous gold subjected to thermal, mechanical, or surface modification studied using gas adsorption isotherms, cyclic voltammetry, thermogravimetric analysis, and scanning electron microscopy. J Mater Chem 22:6733-6745. doi:10.1039/ C2JM16633J

88. Detsi E, Vuković Z, Punzhin S, Bronsveld PM, Onck PR, De Hosson JTM (2012) Fine tuning the feature size of nanoporous silver. Cryst Eng Comm 14:5402-5406. doi:10.1039/C2CE25313E

89. Detsi E, Punzhin S, Onck PR, De Hosson JTM (2012) Direct synthesis of metal nanoparticles with tunable porosity. J Mater Chem 22:4588-4591. doi:10.1039/C2JM15801A

90. Lang X, Zhang L, Fujita T, Ding Y, Chen MW (2012) Threedimensional bicontinuous nanoporous Au/polyaniline hybrid films for high-performance electrochemical supercapacitors. J Power Sour 197:325-329. doi:10.1016/j.jpowsour.2011.09.006

91. Meng F, Ding Y (2011) Sub-micrometer-thick all-solid-state supercapacitors with high power and energy densities. Adv Mater 23:4098-4102. doi:10.1002/adma.201101678

92. Heinze J, Frontana-Uribe BA, Ludwigs S (2010) Electrochemistry of conducting polymers-persistent models and new concepts. Chem Rev 110:4724-4771. doi:10.1021/cr900226k

93. Viswanath RN, Kramer D, Weissmuller J (2008) Adsorbate effects on the surface stress-charge response of platinum electrodes. Electrochim Acta 53:2757-2767. doi:10.1016/j.electacta. 2007.10.049

94. Reis FT, Santos LF, Faria RM, Mencaraglia D (2006) Temperature dependent impedance spectroscopy on polyaniline based devices. IEEE Trans Dielectr Electr Insul 13:1074-1081. doi:10.1109/TDEI.2006.247834

95. Bhadra S, Khastgir D, Singha NK, Lee JH (2009) Progress in preparation, processing and applications of polyaniline. Prog Poly Sci 34:783-810. doi:10.1016/j.progpolymsci.2009.04.003

96. Parker ID (1994) Carrier tunneling and device characteristics in polymer light-emitting diodes. J Appl Phys 75:1656-1666. doi:10.1063/1.356350 
97. Shen Y, Hosseini AR, Wong MH, Malliaras GG (2004) How to make ohmic contacts to organic semiconductors. Chem Phys Chem 5:16-25. doi:10.1002/cphc.200300942

98. Craciun NI et al (2010) Hysteresis-free electron currents in poly(p-phenylene vinylene) derivatives. J Appl Phys 107:124504-124509. doi:10.1063/1.3432744

99. Kronemeijer AJ, Huisman EH, Katsouras I, van Hal PA, Geuns TCT, Blom PWM (2010) Universal scaling in highly doped conducting polymer films. Phys Rev Lett 105:156604-156608. doi:10.1103/PhysRevLett.105.156604

100. Allebrod F, Chatzichristodoulou C, Mollerup PL, Mogensen MB (2012) Electrical conductivity measurements of aqueous and immobilized potassium hydroxide. Int $\mathbf{J}$ Hydrog Energy 37:16505-16514. doi:10.1016/j.ijhydene.2012.02.088

101. Madden JD, Cush RA, Kanigan TS, Hunter IW (2000) Fast contracting polypyrrole actuators. Synth Met 113:185-192. doi:10.1016/S0379-6779(00)00195-8

102. Jin HJ, Weissmüller J (2011) A material with electrically tunable strength and flow stress. Science 332:1179-1182. doi:10. $1126 /$ science. 1202190

103. Blom PWM, de Jong MJM, Vleggaar JJM (1996) Electron and hole transport in poly( $p$-phenylene vinylene) devices. Appl Phys Lett 68:3308. doi:10.1063/1.116583

104. Yan H, Tomizawa K, Ohno H, Toshima N (2003) All-solid actuator consisting of polyaniline film and solid polymer electrolyte. Macromol Mater Eng 288:578-584. doi:10.1002/mame. 200200007

105. Lee YH, Chang CZ, Yau SL, Fan LJ, Yang YW, Yang LY, Itaya K (2009) Conformations of polyaniline molecules adsorbed on $\mathrm{Au}(111)$ probed by in situ STM and ex Situ XPS and NEXAFS. J Am Chem Soc 131:6468-6474. doi:10.1021/ja809263y

106. Botelho AL, Lin X (2009) Am Phys Soc Meeting 54 (http:// meetings.aps.org/link/BAPS.2009.MAR.H20.2)

107. Lin X, Li J, Yip S (2005) Controlling bending and twisting of conjugated polymers via solitons. Phys Rev Lett 95:198303-198307. doi:10.1103/PhysRevLett.95.198303

108. Lin X, Li J, Smela E, Yip S (2005) Polaron-induced conformation change in single polypyrrole chain: an intrinsic actuation mechanism. Int J Quant Chem 102:980-985. doi:10.1002/qua. 20433

109. Vellinga WP, Detsi E, De Hosson JTM (2008) MRS fall meeting-symposium I-reliability and properties of electronic devices on flexible substrates editors: J.R. Greer, J. Vlassak, J. Daniel, T. Tsui. Mater Res Soc Sym Proc 1116:37-42

110. Wan M, Liu LJ, Wang J (1998) Electrical and mechanical properties of polyaniline films-effect of neutral salts added during polymerization. Chin J Poly Sci 16:1-8

111. Krinichnyi VI, Roth H-K, Hinrichsen G, Lux F, Lüders K (2002) EPR and charge transfer in $\mathrm{H}_{2} \mathrm{SO}_{4}$-doped polyaniline. Phys Rev B 65:155205-155219. doi:10.1103/PhysRevB.65.155205

112. Nahar MS, Zhang J (2011) Int Conf Sign Im Proc Appl IPCSIT 21. IACSIT Press, Singapore

113. Choi M-R et al (2011) Polyaniline-based conducting polymer compositions with a high work function for hole-injection layers in organic light-emitting diodes: formation of ohmic contacts. ChemSusChem 4:363-368. doi:10.1002/cssc.201000338
114. Ibach H (1997) The role of surface stress in reconstruction, epitaxial growth and stabilization of mesoscopic structures. Surf Sci Rep 29:195-263. doi:10.1016/S0167-5729(97)00010-1

115. Baughman RH, Cui C, Zakhidov AA, Lqbal Z, Barisci JN, Spinks GM, Wallace GG, Mazzoldi A, Rossi DD, Rinzler AG et al (1999) Carbon nanotube actuators. Science 284:1340-1344. doi:10.1126/science. 284.5418 .1340

116. Mathur A, Erlebacher J (2007) Size dependence of effective Young's modulus of nanoporous gold. Appl Phys Lett 90:061910-061913. doi:10.1063/1.2436718

117. Detsi E, Onck PR, De Hosson JTM (2013) Electrochromic artificial muscles based on nanoporous metal-polymer composites. Appl Phys Lett 103:193101-193104. doi:10.1063/1.4827089

118. Detsi E, Salverda M, Onck PR, De Hosson JTM (2014) On the localized surface plasmon resonance modes in nanoporous gold films. J Appl Phys 115:044308-0443016. doi:10.1063/1.4862440

119. Chen CC, Shih WP, Chang PZ, Lai HM, Chang SY, Huang PC, Jeng HA (2015) Onion artificial muscles. Appl Phys Lett 106:183702-183711

120. Sahaym U, Norton EMG (2008) Advances in the application of nanotechnology in enabling a 'hydrogen economy'. J Mater Sci 43:5395-5429. doi:10.1007/s10853-008-2749-0

121. Esswein AJ, Surendranath Y, Reecea SY, Nocera DG (2011) Highly active cobalt phosphate and borate based oxygen evolving catalysts operating in neutral and natural waters. Energy Environ Sci 4:499-504. doi:10.1039/c0ee00518e

122. Luo J, Im JH, Mayer MT, Schreier M, Nazeeruddin MK, Park N-G, Tilley SD, Fan HJ, Grätzel M (2014) Water photolysis at $12.3 \%$ efficiency via perovskite photovoltaics and earth-abundant catalysts. Science 345:1593-1596. doi:10.1126/science. 1258307

123. Detsi E, Lesel B, Turner C, Liang Y-L, Cook JB, Tolbert SH (2015) Unpublished results

124. McCrory CCL, Jung S, Peters JC, Jaramillo TF (2013) Benchmarking heterogeneous electrocatalysts for the oxygen evolution reaction. J Am Chem Soc 135:16977-16987. doi:10.1021/ ja407115p

125. Chen Q, Sieradzki K (2013) Spontaneous evolution of bicontinuous nanostructures in dealloyed Li-based systems. Nat Mater 12:1102-1106. doi:10.1038/nmat3741

126. Detsi E, Cook JB, Tolbert SH (2015) UCLA Provisional patent application

127. Detsi E, Petrissans X, Cook JB, Dunn B, Tolbert SH (2015) Unpublished results

128. Cook JB, Detsi E, Petrissans X, Liang Y-L, Dunn B, Tolbert SH (2015) Unpublished results

129. Wang J, Lam DCC (2009) Model and analysis of size-stiffening in nanoporous cellular solids. J Mater Sci 44:985-991. doi:10. 1007/s10853-008-3219-4

130. Askes H, Aifantis EC (2011) Comments on "Model and analysis of size-stiffening in nanoporous cellular solids" by Wang and Lam [J. Mater. Sci. 44, 985-991 (2009)]. J Mater Sci 46:6158-6161. doi:10.1007/s10853-011-5637-y 